\title{
Variações florísticas e estruturais do componente arbóreo de uma floresta ombrófila alto-montana às margens do rio Grande, Bocaina de Minas, MG, Brasil ${ }^{1}$
}

\author{
Douglas Antônio de Carvalho ${ }^{2,5}$, Ary Teixeira de Oliveira-Filho ${ }^{3}$, Eduardo van den Berg ${ }^{2}$, Marco Aurélio Leite \\ Fontes $^{3}$, Enivanis de Abreu Vilela ${ }^{2}$, João José Granate de Sá e Melo Marques ${ }^{4}$ e Warley Augusto Caldas Carvalho ${ }^{3}$
}

Recebido em 07/11/2003. Aceito em 20/07/2004

\begin{abstract}
RESUMO - (Variações florísticas e estruturais do componente arbóreo de uma floresta ombrófila alto-montana às margens do rio Grande, Bocaina de Minas, MG, Brasil). Realizou-se o levantamento da comunidade arbórea de uma floresta ombrófila alto-montana

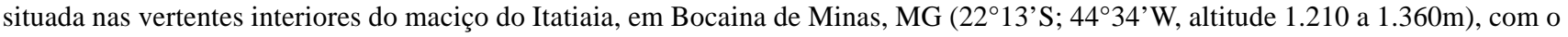
propósito de avaliar as correlações entre variações estruturais e variáveis ambientais relacionadas ao substrato. Foram analisados aspectos da estrutura fisionômica (densidade, área basal e distribuição de tamanhos das árvores) e comunitária (composição, distribuição e diversidade de espécies). Foram alocadas 26 parcelas de 20×20m para amostragem dos indivíduos arbóreos com diâmetro à altura do peito (DAP) $\geq 5 \mathrm{~cm}$, onde também foram coletados dados topográficos e amostras de solo superficial para análises químicas e texturais. Foram registrados 2.574 indivíduos, 221 espécies, 120 gêneros e 54 famílias, bem como três subgrupos de solos: Latossolos Amarelos, Latossolos Vermelho-Amarelos e Latossolos Vermelhos, distribuídos seqüencialmente da baixa para a alta encosta. A comunidade arbórea correspondeu ao perfil florístico e fisionômico das florestas alto-montanas do Sudeste brasileiro, diferenciando daquelas de menores altitudes da mesma região. Uma análise de correspondência canônica detectou um gradiente de distribuição das espécies arbóreas significativamente correlacionado com variações do substrato ao longo da encosta do morro. Houve ainda variações significativas entre os três habitats de solo quanto à diversidade de espécies, mas não para a densidade e área basal das árvores e para as distribuições de altura e diâmetro. O regime de água no solo foi provavelmente a variável ambiental chave, relacionada com as variações florísticas e estruturais da floresta.
\end{abstract}

Palavras-chave: Floresta ombrófila alto-montana, comunidade arbórea, diversidade de espécies, variáveis ambientais

\begin{abstract}
Structural and floristic variations of the arboreal component of a tropical upper montane rainforest on the margin of the Rio Grande, Bocaina de Minas, Brazil). The tree community of an area of upper montane rain forest situated on the interior mountainside of the Itatiaia Range, Brazil (22 ${ }^{\circ} 13^{\prime} \mathrm{S} 44^{\circ} 34^{\prime} \mathrm{W}$, altitude 1,210 to $1,360 \mathrm{~m}$ ), was surveyed with the purpose of assessing the correlations between their structural variations and environmental variables related to the substratum. Variations were analyzed for physiognomic structure (tree density, basal area and size distribution) and community structure (species composition, distribution and diversity). Individual trees with diameter at breast height $(\mathrm{dbh}) \geq 5 \mathrm{~cm}$ were surveyed within 26 plots of $20 \times 20 \mathrm{~m}$ of dimensions where topographic data and samples of surface soil were also collected, the latter for chemical and textural analyses. The survey totaled 2,574 individual trees, 221 species, 120 genera and 54 families, as well as three soil classes: Yellow Latosols, Red-Yellow Latosols, and Red Latosols, distributed sequentially from the slope base to the hilltop. The tree community corresponded to the floristic and physiognomic features of the upper montane forests of southeastern Brazil, differing from those of lower altitudes in the same region. A canonical correspondence analysis detected a main gradient of tree species distribution significantly correlated with variations of the substratum along the hill-slope. There were also significant variations among the three soil habitats for species diversity but not for tree density and basal area and for height and diameter distributions. Ground water regime was probably the key environmental variable related to the floristic and structural variations of the forest.
\end{abstract}

Key words: Tropical upper montane rainforest, tree community, species diversity, environmental variables

\section{Introdução}

As florestas ripárias desempenham importante função ambiental e têm sido, ao longo dos anos, submetidas a impactos antrópicos devastadores e, como consequiência, em várias regiões do Brasil, estão hoje reduzidas a fragmentos esparsos, a maioria deles profundamente perturbados. Ações visando a proteção e recuperação daquelas florestas fazem parte das estratégias de uma nova ordem de pensamento que

\footnotetext{
1 Contrato CEMIG/UFLA/FAEPE

2 Universidade Federal de Lavras, Departamento de Biologia, CEP 37200-000, Lavras, MG, Brasil

3 Universidade Federal de Lavras, Departamento de Ciências Florestais, CEP 37200-000, Lavras, MG, Brasil

4 Universidade Federal de Lavras, Departamento de Ciências do Solo, CEP 37200-000, Lavras, MG, Brasil

5 Autor para correspondência: douglasc@ufla.br
} 
visa a proteção dos recursos naturais, particularmente o suprimento de água, fonte primária da sobrevivência humana. Neste contexto, torna-se necessária a análise da diversidade biológica contida nos atuais fragmentos, por meio de sua quantificação e compreensão da organização espacial da comunidade face às variações do ambiente e a direção das mudanças nos processos ecológicos.

No Estado de Minas Gerais estão sendo desenvolvidos inúmeros estudos dos remanescentes de florestas ripárias nas bacias dos principais rios do estado com o propósito de subsidiar iniciativas de recomposição destas florestas com espécies nativas. Na Região do Alto Rio Grande, sul do estado, o referido rio percorre cerca de $250 \mathrm{~km}$, até iniciar a formação do lago da hidrelétrica de Furnas (Região do Médio Rio Grande) e, neste trajeto, abastece as represas das hidrelétricas de Camargos, Itutinga e Funil. Foram feitos naquela região vários estudos florísticos e fitossociológicos de formações florestais ripárias protetoras de nascentes (Oliveira Filho et al. 1994a; Vilela et al. 1995; van den Berg \& Oliveira-Filho 1999, 2000; P.E. Dalanesi et al., dados não publicados) e situadas ao longo do curso dos rios (Oliveira-Filho et al. 1994b; 1994c; Carvalho et al. 1995a; 1995b; Vilela et al. 2000; Botrel et al. 2002; Rodrigues et al. 2003; Souza et al. 2003). Tais estudos tiveram apoio, a partir de 1990, do contrato firmado entre a Companhia Energética de Minas Gerais (CEMIG) e a Universidade Federal de Lavras (UFLA) e, a partir de 1998, do Projeto de Conservação e Utilização Sustentável da Diversidade Biológica Brasileira (PROBIO). Estes estudos, no entanto, estiveram concentrados em áreas com altitudes variando entre 750 e $1.000 \mathrm{~m}$, deixando de fora florestas situadas em elevações mais altas, inclusive na região das nascentes do próprio rio Grande, situadas nas vertentes interiores do maciço do Itatiaia entre 1.200 e $2.000 \mathrm{~m}$ de altitude.

Para o complexo montanhoso do sudeste brasileiro que inclui as serras da Mantiqueira, do Mar e dos Órgãos, são recentes as descrições florísticas, estruturais e ecológicas de florestas situadas acima de $1.100 \mathrm{~m}$ de altitude, a maioria delas ainda na forma de dissertações universitárias (Baitello \& Aguiar 1982; Meira Neto et al. 1989; Robim et al. 1990; Baitello et al. 1992; Oliveira-Filho \& Machado 1993; Lima \& Guedes-Bruni 1994; M.A.L. Fontes, dados não publicados; A.G. Castro, dados não publicados; G.S. França, dados não publicados; F.A.B. Fernandes, dados não publicados; C.A.N. Ribeiro, dados não publicados; P.E. Dalanesi et al., dados não publicados; Oliveira-
Filho et al. 2004). Para o maciço do Itatiaia, até o presente momento, sua vegetação foi objeto de estudos detalhados apenas do lado do estado do Rio de Janeiro, particularmente no Parque Nacional de Itatiaia, destacando-se os estudos descritivos pioneiros realizados por Barros $(1948 ; 1955 ; 1958 ; 1959)$ e Brade (1956) e a primeira descrição quantitativa do componente arbóreo de uma floresta ombrófila realizada por R.R. Guedes-Bruni (dados não publicados). Desta forma, as florestas da vertente interior do maciço do Itatiaia, em Minas Gerais, são ainda muito pouco conhecidas. Nesta região, o vale que aloja as nascentes do rio Grande apresenta atualmente uma cobertura florestal muito pobre. Este quadro resulta de um processo indiscriminado de abate de árvores que atendeu as necessidades madeireiras, principalmente do eixo Rio de Janeiro-São Paulo, durante boa parte do século passado. $\mathrm{O}$ desmatamento foi particularmente acelerado nos anos 1940, durante a construção da Usina Siderúrgica Nacional, em Volta Redonda, quando aumentou a demanda regional de madeira e carvão.

O presente trabalho foi conduzido em um fragmento florestal adjacente ao curso do rio Grande, no município de Bocaina de Minas, MG, com o objetivo de verificar as correlações entre as variações da estrutura da comunidade arbórea e as variáveis ambientais relacionadas ao substrato. Os aspectos estruturais analisados referem-se tanto à estrutura fisionômica (densidade, área basal e distribuição de alturas e diâmetros das árvores) como à estrutura comunitária (composição, distribuição e diversidade de espécies). Compreende-se como substrato o conjunto de variáveis topográficas e edáficas determinantes do status nutricional mineral do solo e de seu regime hídrico.

\section{Material e métodos}

A área estudada, conhecida localmente como Mata da Cachoeira do Rio Grande, corresponde a um fragmento de aproximadamente 10ha de floresta ombrófila alto-montana sensu Oliveira-Filho \& Fontes (2000) ou floresta ombrófila densa montana sensu IBGE (Veloso et al. 1991). Localiza-se às margens do rio Grande a cerca de $10 \mathrm{~km}$ a jusante de sua nascente nas vertentes interiores do maciço do Itatiaia, município de Bocaina de Minas, MG, nas coordenadas de $22^{\circ} 13^{\prime} 03^{\prime \prime}$ a $22^{\circ} 13^{\prime} 06^{\prime \prime}$ de latitude Sul e 4432'20" a 4432'27' de longitude Oeste e a uma altitude que varia de 1.210 a $1.360 \mathrm{~m}$ (Fig. 1). O fragmento reveste uma encosta que flanqueia a margem esquerda do rio Grande e apresenta bordas abruptas nos seus limites 


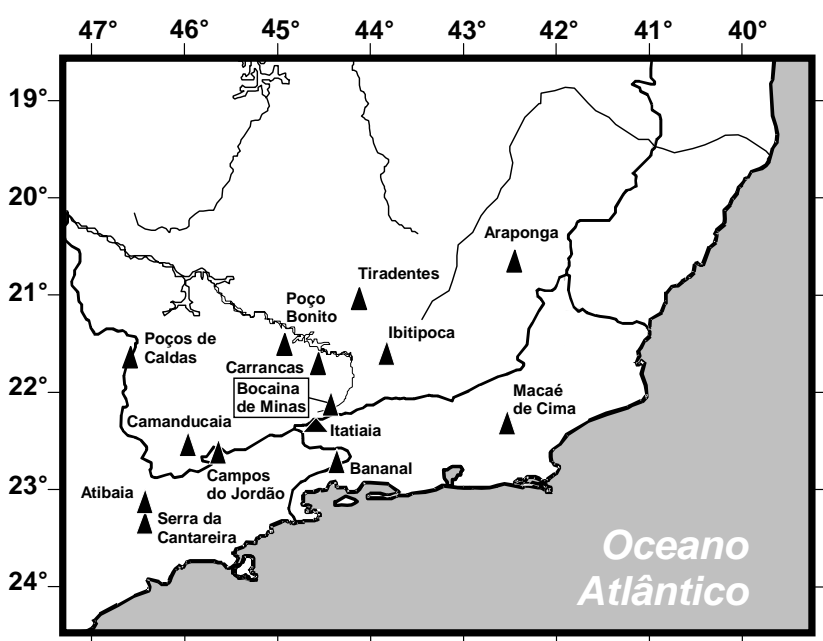

Figura 1. Localização geográfica da área de estudos, Bocaina de Minas, no Sudeste do Brasil e de outras 13 áreas de floresta inventariadas na região e utilizadas nas comparações florísticas. Todas as áreas estão situadas acima dos $1.000 \mathrm{~m}$ de altitude, exceto Itatiaia (cerca de 800m). com pastagens circunvizinhas. Devido ao intenso desmatamento sofrido pela região no passado, a Mata da Cachoeira do Rio Grande é um dos raros remanescentes florestais em melhor estado de conservação. No entanto, o setor adjacente à margem do rio foi alterado para fins de lazer e o fragmento vem sofrendo ainda o impacto da penetração do gado.

De acordo com o banco de dados referido em Oliveira-Filho e Fontes (2000), o clima da região é do tipo $\mathrm{Cb}$ (úmido mesotérmico) de Köppen (subtropical); a temperatura média anual é de $16,7^{\circ} \mathrm{C}$, com médias mensais variando de $13,0^{\circ} \mathrm{C}$ em julho a $19,7^{\circ} \mathrm{C}$ em janeiro; a precipitação média anual é de $2.108 \mathrm{~mm}$, com médias mensais variando de $341 \mathrm{~mm}$, no trimestre mais chuvoso (dezembro a fevereiro), a $35 \mathrm{~mm}$, no trimestre mais seco (junho a agosto).

A comunidade arbórea foi amostrada em 26 parcelas de $20 \times 20 \mathrm{~m}$, dispostas sistematicamente em sete alinhamentos perpendiculares à inclinação maior
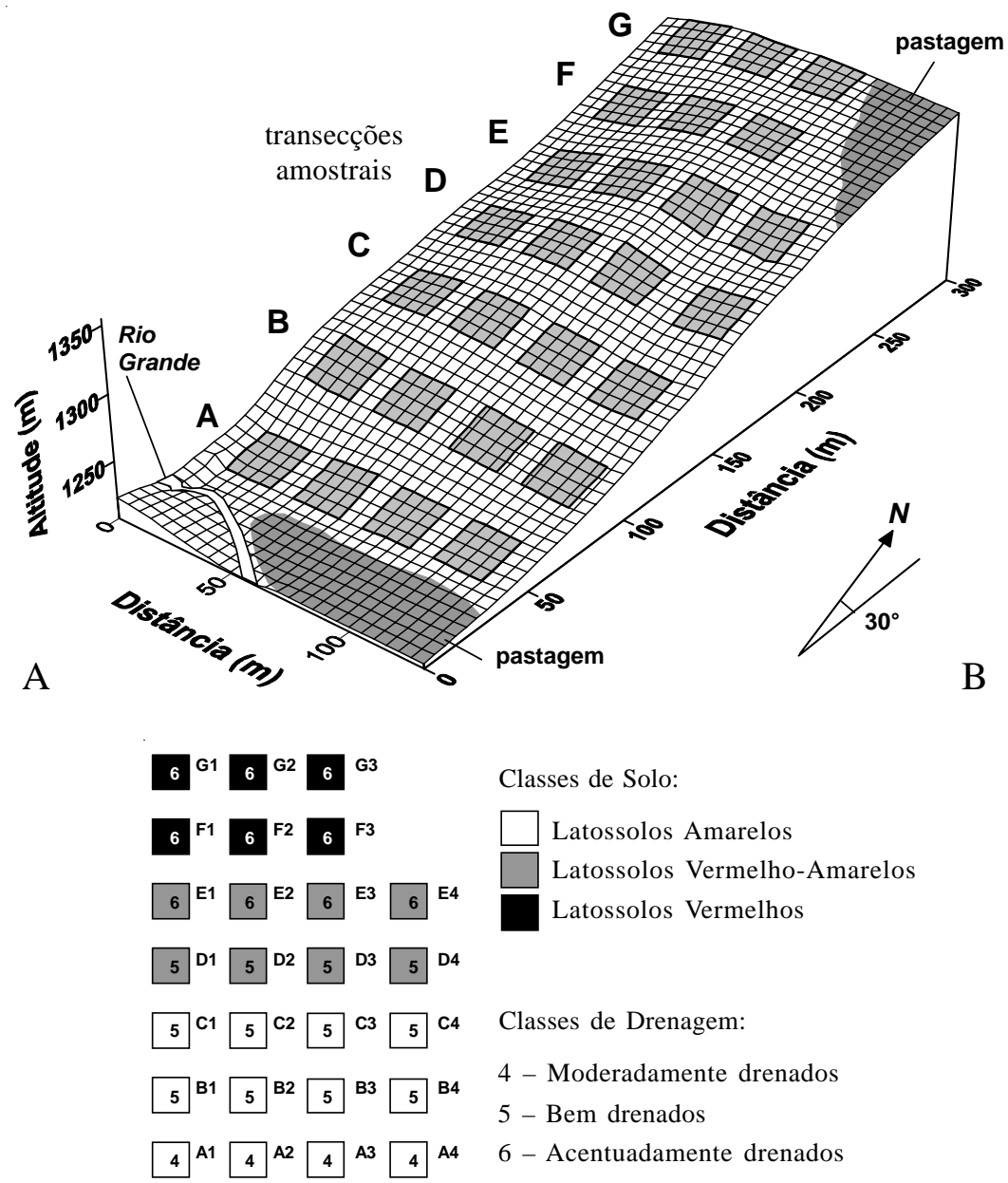

Figura 2. A. Grade de superfície mostrando a topografia da área da Mata da Cachoeira do Rio Grande, Bocaina de Minas, MG, e a distribuição das 26 parcelas de $20 \times 20 \mathrm{~m}$ utilizadas para amostrar a comunidade arbórea. O espaçamento entre as linhas da grade é de $5 \mathrm{~m}$. B. Distribuição das classes de solos nas parcelas amostrais. 
da encosta (A-G), totalizando 1,04ha de área amostrada (Fig. 2). Os espaçamentos entre alinhamentos e entre parcelas do mesmo alinhamento foram de $20 \mathrm{~m}$ e $10 \mathrm{~m}$, respectivamente. O número de parcelas de cada alinhamento foi determinado pelo contorno do fragmento.

Um levantamento topográfico foi realizado na área, com auxílio de trena, bússola e clinômetro, a partir do qual foi produzida uma representação tridimensional da área (Fig. 2A) e foram extraídas três variáveis topográficas por parcela: (a) distância vertical até o rio, obtida da diferença entre a cota média dos quatro vértices da parcela e a cota da margem do rio Grande; (b) desnível, obtido da diferença entre as cotas máxima e mínima; e (c) declividade média, obtida da média da declividade dos quatro lados das parcelas. Estas foram obtidas como meio de avaliação indireta das condições hidrológicas dos solos, conforme adotado por Botrel et al. (2002).

Os solos predominantes em cada parcela foram classificados no campo de acordo com o novo Sistema Brasileiro de Classificação dos Solos (EMBRAPA 1999), chegando até o nível de subgrupo (ou $4^{\circ}$ nível categórico) e incluindo as classes de drenagem. No centro de cada parcela, foram coletadas amostras simples do solo superficial (0-20 cm de profundidade) de cerca de 500ml. Efetuaram-se análises químicas e texturais das amostras no Laboratório de Análise de Solos da UFLA, seguindo o protocolo da EMBRAPA (1997). As variáveis de solo obtidas foram: $\mathrm{pH}$; teores de $\mathrm{P}, \mathrm{K}, \mathrm{Ca}, \mathrm{Mg}, \mathrm{Al}, \mathrm{H}+\mathrm{Al}$; soma de bases (SB); saturação por bases (valor $\mathrm{V}$ ); matéria orgânica e teores de areia, silte e argila.

Em cada parcela foram registrados todos os indivíduos arbóreos vivos e com circunferência a altura de $1,30 \mathrm{~m}$ (CAP) igual ou superior a $15,7 \mathrm{~cm}$, o que equivale a um diâmetro (DAP) de $5,0 \mathrm{~cm}$. Os indivíduos com caules divididos desde a base foram incluídos no levantamento quando a área basal total dos caules correspondia a CAP $\geq 15,7 \mathrm{~cm}$. Cada indivíduo foi marcado com etiqueta de alumínio numerada, sendo registrados seu número, a espécie, o valor das CAPs, medido com fita métrica, e a altura total, estimada com auxílio de vara graduada. Foram coletadas amostras de material botânico dos espécimes registrados nas parcelas para posterior identificação. A herborização do material botânico foi feita no Herbário do Departamento de Biologia da Universidade Federal de Lavras (Herbário ESAL) e a coleção testemunho foi incorporada ao acervo do mesmo. A identificação do material botânico foi realizada com a utilização de coleções botânicas já existentes no Herbário ESAL e também por meio de consultas à literatura, a especialistas e a coleções dos Herbários do Jardim Botânico do Rio de Janeiro (RB), Instituto de Botânica de São Paulo (SP) e Universidade Estadual de Campinas (UEC). As identificações taxonômicas de angiospermas (todas, exceto Cyatheacae, Araucariaceae e Podocarpaceae) seguem o sistema Angiosperm Phylogeny Group II (APG II 2003).

A estrutura da comunidade arbórea foi descrita a partir do cálculo dos seguintes parâmetros quantitativos por espécie: altura máxima, número de indivíduos, número de parcelas com ocorrência da espécie, área basal e valor de cobertura (VC), este último obtido da soma dos valores relativos de número de indivíduos e área basal (Rodrigues 1988). Os parâmetros foram calculados para a amostra total e para as subamostras correspondentes às três classes de solos encontradas. Foram preparadas distribuições do número de indivíduos por classes de diâmetro e altura para as mesmas classes de solo. No caso dos diâmetros, foram empregados intervalos de classe com amplitudes crescentes para compensar o forte decréscimo da densidade nas classes de tamanho maiores, típico da distribuição em Jinvertido. Estes intervalos permitem uma melhor representação das classes diamétricas maiores e de baixa densidade, o que é desejável em comparações gráficas (Oliveira-Filho et al. 2001). As distribuições dos números de indivíduos por classes de diâmetro e de altura para os diferentes tipos de solos foram comparadas par a par por meio do teste $\chi^{2}$ (Zar 1996).

Para a determinação da diversidade de espécies foram calculados os índices de diversidade de Shannon $\left(H^{\prime}\right)$ e de equabilidade de Pielou ( $\left.J^{\prime}\right)$ em base logarítmica natural (Brower \& Zar 1984) para a amostra total e subamostras para cada uma das três classes de solos. Os valores de $H^{\prime}$ obtidos para duas das classes de solos mais representativas foram comparados pelo teste de $t$ de Hutcheson (Zar 1996). Para evitar o problema causado por diferentes intensidades amostrais em comparações entre índices, foram extraídas aleatoriamente subamostras de seis parcelas nos dois subgrupos de solo com maior número de parcelas. Foram calculados índices de similaridade florística de Sørensen (Brower \& Zar 1984) entre a listagem de espécies obtida no presente estudo e outras 13 listagens produzidas para as áreas indicadas na Fig. 1, todas elas de florestas alto-montanas sensu Oliveira-Filho \& Fontes (2000), isto é, acima de $1.100 \mathrm{~m}$, exceto Itatiaia $(800 \mathrm{~m})$, mantida devido à sua proximidade da área de estudos. 
Para analisar as correlações entre os gradientes ambientais e vegetacionais foi empregada uma análise de correspondência canônica (CCA) (ter Braak 1987) utilizando o programa PC-ORD for Windows versão 4.14 (McCune \& Mefford 1999). A matriz de abundância das espécies foi constituída do $\mathrm{VC}$ por parcela das 49 espécies que apresentaram $\mathrm{VC}>1$ na amostra total. O VC por parcela foi obtido da soma do número de indivíduos e da área total da espécie na parcela, ambos expressos como frações da amostra total. De acordo com as recomendações de ter Braak (1995), os valores de abundância foram transformados pela expressão $\log _{10}(\mathrm{a}+1)$ para compensar os desvios causados por alguns poucos valores muito elevados. Os subgrupos de solo foram discriminados no diagrama de ordenação das parcelas para facilitar a interpretação dos padrões emergentes.

A matriz de variáveis ambientais incluiu, a princípio, as três variáveis topográficas, a classe de drenagem dos solos, além de todas as 13 variáveis químicas e texturais dos solos, totalizando 17 variáveis. As classes de drenagem dos solos foram expressas como variável ordinal ('ranking'), atribuída às categorias descritas pela EMBRAPA (1999): 4 - moderadamente drenado, 5 - bem drenado e 6 - acentuadamente drenado (outras classes de drenagem não foram representadas). Após realizar uma CCA preliminar, foram eliminadas 13 variáveis ambientais fracamente correlacionadas ou altamente redundantes com outras variáveis. A CCA final foi processada com as quatro variáveis mais representativas e mais fortemente correlacionadas com os eixos de ordenação: a cota média e os teores de matéria orgânica, areia e de argila do solo.

\section{Resultados}

Variáveis topográficas e edáficas - As três classes de solos identificadas no fragmento florestal (Fig. 2B) foram: (a) os Latossolos Amarelos Distróficos típicos (LAd), situados na baixa encosta e classificados como moderadamente a bem drenados conforme a posição topográfica; (b) os Latossolos Vermelho-Amarelos Distróficos típicos (LVAd2), situados na meia encosta e classificados como bem drenados a acentuadamente drenados conforme a posição topográfica; e (c) os Latossolos Vermelhos Distróficos típicos (LVd2), situados na alta encosta e classificados como acentuadamente drenados. A partir deste ponto as três classes de solo são referidas apenas pelos dois primeiros nomes.

As diferenças entre as classes de solo quanto às variáveis topográficas e variáveis químicas e texturais dos solos são apresentadas na Tabela 1. Devido à sua distribuição catenária, a cota média e a distância vertical

Tabela 1. Variáveis topográficas e químicas e texturais dos solos em 26 amostras de solo superficial (0-20cm de profundidade) coletadas nas parcelas empregadas para amostrar a Mata da Cachoeira do Rio Grande, Bocaina de Minas, MG. Os valores são médias \pm desvios padrão das $N$ amostras de cada uma das três classes de solo. Onde análises de variância indicaram diferenças significativas entre as classes de solo, médias seguidas da mesma letra não diferiram significativamente entre si pelo teste de Tukey $(P \leq 0.05)$.

\begin{tabular}{|c|c|c|c|c|c|}
\hline \multirow[b]{3}{*}{ Variáveis } & \multicolumn{3}{|c|}{ Latossolos } & & \\
\hline & Amarelos & Vermelho-Amarelos & Vermelhos & \multicolumn{2}{|c|}{ ANOVA } \\
\hline & $N=12$ & $N=8$ & $N=6$ & $F$ & $P$ \\
\hline Cota média (m) & $1243,4 \pm 21,2^{\mathrm{c}}$ & $1299,8 \pm 10,7^{\mathrm{b}}$ & $1338,0 \pm 11,4^{\mathrm{a}}$ & 70,82 & $<10^{-6}$ \\
\hline Distância vertical até o rio (m) & $33,4 \pm 21,2^{\mathrm{c}}$ & $89,8 \pm 0,7^{b}$ & $128,0 \pm 11,4^{\mathrm{a}}$ & 70,82 & $<10^{-6}$ \\
\hline Desnível (m) & $13,0 \pm 2,9$ & $15,2 \pm 3,2$ & $12,9 \pm 3,6$ & 1,43 & 0,260 \\
\hline Declividade média (graus) & $32,7 \pm 5,9$ & $36,9 \pm 5,8$ & $32,4 \pm 7,0$ & 1,38 & 0,271 \\
\hline $\mathrm{pH}$ em $\mathrm{H}_{2} \mathrm{O}$ & $4,3 \pm 0,1^{\mathrm{b}}$ & $4,5 \pm 0,2^{\mathrm{a}}$ & $4,5 \pm 0,2^{\mathrm{ab}}$ & 3,94 & 0,034 \\
\hline $\mathrm{P}-\operatorname{Mehlich}\left(\mathrm{mg} / \mathrm{dm}^{3}\right)$ & $1,7 \pm 0,3$ & $2,1 \pm 0,6$ & $1,6 \pm 0,5$ & 3,16 & 0,061 \\
\hline $\mathrm{K}^{+}\left(\mathrm{mg} / \mathrm{dm}^{3}\right)$ & $14,0 \pm 6,0$ & $16,0 \pm 10,0$ & $15,0 \pm 6,0$ & 0,33 & 0,721 \\
\hline $\mathrm{Ca}^{++}\left(\mathrm{cmolc} / \mathrm{dm}^{3}\right)$ & $0,3 \pm 0,1^{b}$ & $0,4 \pm 0,1^{\mathrm{a}}$ & $0,3 \pm 0,1 \mathrm{ab}$ & 3,41 & 0,050 \\
\hline $\mathrm{Mg}^{++}\left(\mathrm{cmolc} / \mathrm{dm}^{3}\right)$ & $0,1 \pm 0,0^{\mathrm{b}}$ & $0,2 \pm 0,1^{\mathrm{a}}$ & $0,1 \pm 0,0^{\mathrm{ab}}$ & 4,89 & 0,016 \\
\hline $\mathrm{Al}^{+++}\left(\mathrm{cmolc} / \mathrm{dm}^{3+}\right)$ & $2,0 \pm 0,2^{a}$ & $1,6 \pm 0,5^{b}$ & $1,5 \pm 0,3^{b}$ & 6,65 & 0,005 \\
\hline $\mathrm{H}^{+}+\mathrm{Al}^{+++}\left(\mathrm{cmolc} / \mathrm{dm}^{3}\right)$ & $11,4 \pm 1,6$ & $10,3 \pm 2,3$ & $10,1 \pm 1,4$ & 1,37 & 0,273 \\
\hline $\mathrm{SB}$ - soma de bases $\left(\mathrm{cmolc} / \mathrm{dm}^{3}\right)$ & $0,4 \pm 0,1^{b}$ & $0,6 \pm 0,2^{a}$ & $0,5 \pm 0,2^{a b}$ & 3,55 & 0,045 \\
\hline V - saturação p/bases (\%) & $3,7 \pm 0,7^{\mathrm{b}}$ & $5,9 \pm 2,3^{a}$ & $4,5 \pm 1,4^{\mathrm{ab}}$ & 5,13 & 0,014 \\
\hline Matéria orgânica (dag/kg) & $3,1 \pm 0,5^{\mathrm{b}}$ & $3,6 \pm 0,9^{a b}$ & $4,4 \pm 0,5^{\text {a }}$ & 7,96 & 0,002 \\
\hline Areia $(\%)$ & $52,6 \pm 3,3^{\mathrm{a}}$ & $52,6 \pm 3,6^{\mathrm{a}}$ & $46,3 \pm 2,7^{b}$ & 8,01 & 0,002 \\
\hline Silte $(\%)$ & $12,8 \pm 3,9$ & $12,8 \pm 2,7$ & $10,3 \pm 2,1$ & 1,34 & 0,280 \\
\hline Argila (\%) & $34,6 \pm 4,2^{b}$ & $34,6 \pm 4,2^{a b}$ & $43,6 \pm 3,9^{a}$ & 10,32 & $<10^{-3}$ \\
\hline
\end{tabular}


até o rio variaram significativamente entre as três classes de solo. No entanto, não foram encontradas diferenças significativas para as outras duas variáveis topográficas, desnível e declividade média. A maioria das variáveis químicas e texturais dos solos diferiu significativamente entre as três classes de solo; as exceções foram os teores de $\mathrm{P}, \mathrm{K}$ e $\mathrm{H}+\mathrm{Al}$ e as proporções de silte. A maior parte das diferenças foi detectada entre os Latossolos Amarelos e Latossolos Vermelho-Amarelos, ficando os primeiros com teores de $\mathrm{Al}$ significativamente mais altos e $\mathrm{pH}$, teores de $\mathrm{Ca}$ e Mg, saturação por bases, soma de bases e proporções de argila significativamente mais baixos que os últimos. As proporções de areia foram significativamente mais baixas nos Latossolos Vermelhos que nas duas outras classes de solo, ao passo que os teores de matéria orgânica e de argila foram significativamente maiores nos Latossolos Vermelhos que nos Latossolos Amarelos.

Florística, estrutura e diversidade da comunidade arbórea - Foram identificadas 221 espécies pertencentes a 120 gêneros e 54 famílias (Tab. 2), sendo que duas variedades foram identificadas para a espécie Vernonanthura diffusa (Asteracae). Destacaram-se as famílias Melastomataceae e Myrtaceae, com 20 espécies cada, seguidas de Fabaceae e Lauraceae (16), Annonaceae (12), Solanaceae (11), Euphorbiaceae (10), Asteraceae (9) e Cyatheaceae e Rubiaceae (7), que juntas representaram $58 \%$ das espécies. As famílias representadas por somente uma espécie somaram 22 (40\%). Os gêneros com maiores números de espécies foram Miconia, com 12, Solanum (7); Ocotea (6); Casearia, Eugenia, Myrcia, Myrsine, Nectandra e Tibouchina (5); e Guatteria, Rollinia,

Tabela 2. Espécies arbóreas registradas na Mata da Cachoeira do Rio Grande, Bocaina de Minas, MG, dispostas em ordem alfabética de famílias botânicas e acompanhadas de seus respectivos números de registro (Rg) no Herbário ESAL e parâmetros quantitativos obtidos na amostra de 26 parcelas de 20×20m: h = altura máxima; $\mathrm{N}=$ número de indivíduos; $\mathrm{P}=$ número de parcelas com ocorrência da espécie; $\mathrm{AB}=$ área basal; e $\mathrm{VC}=$ valor de cobertura. Espécies com $\mathrm{N}=$ 'Flora' foram registradas apenas fora das parcelas amostrais.

\begin{tabular}{|c|c|c|c|c|c|c|}
\hline Famílias/Espécies & $\operatorname{Rg}$ & $\begin{array}{c}\mathrm{h} \\
(\mathrm{m})\end{array}$ & $\mathrm{N}$ & $\mathrm{P}$ & $\begin{array}{l}\mathrm{AB} \\
\left(\mathrm{m}^{2}\right)\end{array}$ & $\mathrm{VC}$ \\
\hline \multicolumn{7}{|l|}{ ANACARDIACEAE } \\
\hline Tapirira guianensis Aublet & 12170 & 13,0 & 6 & 6 & 0,047 & 0,37 \\
\hline T. obtusa (Benth.) Mitchell & 12330 & 22,0 & 25 & 15 & 0,969 & 3,77 \\
\hline \multicolumn{7}{|l|}{ ANNONACEAE } \\
\hline Annona cacans Warm. & 14937 & 14,0 & 10 & 6 & 0,164 & 0,86 \\
\hline Cymbopetalum brasiliense (Vell.) Benth. & 17230 & 9,0 & 4 & 3 & 0,025 & 0,23 \\
\hline Duguetia salicifolia R.E. Fries & 17231 & 10,5 & 4 & 4 & 0,019 & 0,21 \\
\hline Guatteria australis A.St.-Hil. & 16220 & 15,0 & 11 & 7 & 0,154 & 0,87 \\
\hline G. latifolia (Mart.) R.E. Fries & 17232 & 6,0 & 4 & 2 & 0,018 & 0,21 \\
\hline G. nigrescens Mart. & 14871 & 11,0 & 10 & 7 & 0,072 & 0,60 \\
\hline G. pubens (Mart.) R.E. Fries & 17233 & 14,0 & 79 & 22 & 0,541 & 4,63 \\
\hline Rollinia dolabripetala (Raddi) R.E. Fries & 16221 & 13,0 & 4 & 4 & 0,039 & 0,27 \\
\hline R. laurifolia Schltdl. & 16726 & & Flora & & & \\
\hline R. sericea (R.E. Fries) R.E. Fries & 16727 & 10,0 & 4 & 4 & 0,016 & 0,20 \\
\hline R. sylvatica (A. St.-Hil.) Mart. & 17234 & 12,0 & 8 & 4 & 0,044 & 0,44 \\
\hline Xylopia brasiliensis Sprengel & 12137 & & Flora & & & \\
\hline \multicolumn{7}{|l|}{ APOCYNACEAE } \\
\hline Aspidosperma parvifolium A. DC. & 14867 & 13,0 & 2 & 2 & 0,036 & 0,18 \\
\hline A. spruceanum Benth. & 17235 & 25,0 & 3 & 3 & 0,327 & 1,06 \\
\hline \multicolumn{7}{|l|}{ AQUIFOLIACEAE } \\
\hline Ilex brevicuspis Reissek & 17236 & 11,5 & 3 & 2 & 0,054 & 0,27 \\
\hline I. cerasifolia Reissek & 17237 & 9,0 & 1 & 1 & 0,016 & 0,09 \\
\hline I. conocarpa Reissek & 17238 & 13,0 & 2 & 2 & 0,015 & 0,12 \\
\hline I. theezans Mart. & 17239 & & Flora & & & \\
\hline \multicolumn{7}{|l|}{ ARALIACEAE } \\
\hline Oreopanax capitatus (Jacquin) Decne \& Planchon & 17240 & 4,0 & 1 & 1 & 0,003 & 0,05 \\
\hline Schefflera acuminata (E. Marchal) D. Frodin & 17241 & 10,5 & 2 & 2 & 0,009 & 0,10 \\
\hline S. longepetiolata (E. Marchal) D. Frodin & 17242 & 18,0 & 20 & 16 & 0,238 & 1,47 \\
\hline
\end{tabular}


Tabela 2 (continuação)

Famílias/Espécies

$\operatorname{Rg}$

$\begin{array}{cccc}\mathrm{h} & \mathrm{N} & \mathrm{P} & \mathrm{AB} \\ (\mathrm{m}) & & & \left(\mathrm{m}^{2}\right)\end{array}$

ARECACEAE

Geonoma schottiana Mart.

15165

ASTERACEAE

Baccharis serrulata Pers.

Eremanthus erythropappus (DC.) MacLeish

17244

16228

Gochnatia paniculata (Less.) Cabrera

15151

Piptocarpha macropoda Baker

17245

P. regnellii (Sch. Bip.) Cabrera

17246

Stifftia chrysantha Mikan

17246

Vernonanthura diffusa var. approximata Baker $\quad 17248$

$V$. diffusa var. macrocephala Hieron.

17249

$V$. discolor (Less.) H. Robinson

17250

BIGNONIACEAE

Cybistax antisyphillitica Mart.

16747

Jacaranda macrantha Cham.

16390

Tabebuia chrysotricha (Mart.) Standley

17251

T. vellosoi Toledo

17252

BORAGINACEAE

Cordia ecalyculata Vell.

C. superba Cham.

17253

14618

CELASTRACEAE

Maytenus glazioviana Loes.

M. salicifolia Reissek

17254

17255

3,0

2

8,0

(10

1

2

0,004

0,09

CHLORANTHACEAE

Hedyosmum brasiliense Mart.

15170

14,0

Flora

Flora

19,0

10

$1 \quad 0,005$

0,05

CLETHRACEAE

Clethra scabra Pers.

CLUSIACEAE

Clusia criuva Cambess.

C. fragrans Gardner

Tovomitopsis saldanhae Engler

Vismia brasiliensis Choisy

20,0

18,0

20,0

1

Flora

29

12

28

AB

VC

$\left(m^{2}\right)$

Flora

7,5

7,0

11,0

1

3

$\begin{array}{rll}8 & 0,165 & 0,86 \\ 1 & 0,025 & 0,11 \\ & & \\ 11 & 0,677 & 3,08 \\ 5 & 0,344 & 1,46 \\ 12 & 0,399 & 2,24\end{array}$

CUNONIACEAE

Lamanonia ternata Vell.

CYATHEACEAE

Alsophila setosa Kaulf

A. sternbergii (Sternb.) Conant

Cyathea corcovadensis (Raddi) Domin

C. delgadii Sternb.

C. dichromatolepis (Fée) Domin

C. phalerata Mart.

Sphaeropteris gardneri (Hooker) Tryon

18,0

5

\section{1}

0,008

0,008

0,06

$30,008 \quad 0,14$

5

3

0,033

0,29

Flora

$5 \quad 0,172$

0,77

6,5

11,5

1

1
3

1

0,002

0,021

0,05

0,18

Flora

14890

17,0

$$
34
$$

14

0,457

2,64

14390

17256

17257

15164

10,5

14,0

Flora

2

12

8,0

17258

25,0

17259

14623

17260

17261

17262

17263

17264

DICKSONIACEAE

Dicksonia sellowiana Hooker

17265

ELAEOCARPACEAE

Sloanea guianensis (Aublet) Benth.

S. monosperma Vell.

17266

17267

ERYTHROXYLACEAE

Erythroxylum pelleterianum A. St.-Hil.

17560

EUPHORBIACEAE

Alchornea glandulosa Poepp. \& Endl.

A. sidifolia Müll. Arg.

A. triplinervia (Sprengel) Müll. Arg.

16783

17268

15463

Croton floribundus Sprengel

C. organensis Baillon

14879

17269

C. salutaris Casar.

17270

$\begin{array}{lll}2 & 0,023 & 0,14 \\ 9 & 0,063 & 0,65 \\ 1 & 0,003 & 0,05\end{array}$

84

23

3,010

11,96

20
Flora

$$
4
$$

0,132

1,16

53

59

$$
13
$$

0,613

0,366

0,020

3,83

3,35

0,14

3
Flora

$2 \quad 0,027$

0,19

\section{(2)}

$$
2,5
$$$$
8,0
$$$$
7,0
$$

2

$$
1
$$

0,042

0,20

2
1

$$
4,5
$$

2

$2 \quad 0,022$

0,14

0,06

0,10

Flora

14,0

30,0

12,0

17,0

28
164
Flora
4
77

$\begin{array}{rcc}10 & 0,603 & 2,83 \\ 26 & 1,860 & 11,75 \\ & & \\ 3 & 0,066 & 0,35 \\ 14 & 0,455 & 4,31 \\ & & \text { сопtinua }\end{array}$


Tabela 2 (continuação)

\begin{tabular}{|c|c|c|c|c|c|c|}
\hline Famílias/Espécies & $\mathrm{Rg}$ & $\begin{array}{c}\mathrm{h} \\
(\mathrm{m})\end{array}$ & $\mathrm{N}$ & $\mathrm{P}$ & $\begin{array}{l}\mathrm{AB} \\
\left(\mathrm{m}^{2}\right)\end{array}$ & $\mathrm{VC}$ \\
\hline \multicolumn{7}{|l|}{ EUPHORBIACEAE } \\
\hline Manihot pilosa Pohl & 17171 & 6,0 & 2 & 1 & 0,005 & 0,09 \\
\hline Pera glabrata (Schott) Poepp. & 11078 & 32,0 & 12 & 9 & 0,336 & 1,44 \\
\hline Sapium glandulosum (L.) Morong & 14629 & 9,0 & 8 & 7 & 0,031 & 0,40 \\
\hline Tetrorchidium parvulum Müll. Arg. & 17272 & 11,0 & 34 & 14 & 0,263 & 2,08 \\
\hline \multicolumn{7}{|l|}{ FABACEAE } \\
\hline Albizia polycephala (Benth.) Killip & 17280 & 25,0 & 8 & 6 & 0,065 & 0,50 \\
\hline Dalbergia villosa (Benth.) Benth. & 17276 & 15,0 & 21 & 11 & 0,150 & 1,25 \\
\hline Erythrina falcata Benth. & 17277 & & Flora & & & \\
\hline Inga sessilis (Vell.) Mart. & 17281 & 14,0 & 4 & 4 & 0,043 & 0,28 \\
\hline I. striata Benth. & 17282 & 12,0 & 2 & 2 & 0,014 & 0,12 \\
\hline I. vulpina Mart. & 17283 & & Flora & & & \\
\hline Machaerium nyctitans (Vell.) Benth. & 16846 & 8,0 & 1 & 1 & 0,008 & 0,06 \\
\hline M. reticulatum (Peyr.) Pers. & 17278 & 6,0 & 1 & 1 & 0,009 & 0,07 \\
\hline M. villosum Vogel & 12425 & 11,0 & 2 & 2 & 0,025 & 0,15 \\
\hline Mimosa artemisiana Heringer \& Paula & 17284 & & Flora & & & \\
\hline M. scabrela Benth. & 17285 & & Flora & & & \\
\hline Ormosia fastigiata Tul. & 17279 & 15,0 & 7 & 5 & 0,082 & 0,51 \\
\hline Poeppigia procera Presl. & 17273 & 8,0 & 26 & 9 & 0,230 & 1,67 \\
\hline Sclerolobium rugosum Mart. & 17274 & 16,0 & 26 & 6 & 0,223 & 1,65 \\
\hline Senna macranthera (Vell.) Irwin \& Barneby & 16496 & 11,5 & 16 & 10 & 0,180 & 1,14 \\
\hline S. multijuga (L.C. Rich.) Irwin \& Barneby & 17175 & 17,0 & 10 & 7 & 0,061 & 0,57 \\
\hline \multicolumn{7}{|l|}{ LAMIACEAE } \\
\hline Aegiphila fluminensis Vell. & 17374 & 16,0 & 6 & 4 & 0,044 & 0,36 \\
\hline Hyptidendron asperrimum (Epling) Harley & 17290 & 19,0 & 28 & 16 & 1,204 & 4,57 \\
\hline \multicolumn{7}{|l|}{ LAURACEAE } \\
\hline Cinnamomum glaziovii (Mez) Vattimo & 16246 & & Flora & & & \\
\hline Endlicheria paniculata (Sprengel) Macbr. & 17291 & 8,0 & 5 & 2 & 0,033 & 0,29 \\
\hline Nectandra grandiflora Nees & 16247 & 7,0 & 1 & 1 & 0,002 & 0,04 \\
\hline N. lanceolata Nees & 17292 & & Flora & & & \\
\hline N. membranacea (Swartz) Griseb. & 17293 & 10,5 & 7 & 6 & 0,052 & 0,42 \\
\hline N. oppositifolia Nees & 12411 & 17,0 & 15 & 10 & 0,227 & 1,24 \\
\hline N. puberula (Schott) Nees & 17294 & 6,0 & 1 & 1 & 0,002 & 0,04 \\
\hline Ocotea aciphylla (Nees) Mez & 16249 & 13,0 & 11 & 4 & 0,079 & 0,66 \\
\hline O. corymbosa (Meisner) Mez & 13140 & 30,0 & 39 & 16 & 1,171 & 4,90 \\
\hline O. elegans $\mathrm{Mez}$ & 15399 & & Flora & & & \\
\hline O. longifolia Kunth & 17295 & 11,5 & 6 & 3 & 0,025 & 0,30 \\
\hline O. odorifera (Vell.) Rohwer & 15047 & & Flora & & & \\
\hline O. puberula (Rich.) Nees & 17385 & & Flora & & & \\
\hline Persea fulva Kopp & 17296 & & Flora & & & \\
\hline P. major Kopp & 17297 & 23,0 & 9 & 6 & 0,449 & 1,65 \\
\hline P. pyrifolia Nees \& Mart. & 17298 & 15,0 & 3 & 2 & 0,242 & 0,82 \\
\hline \multicolumn{7}{|l|}{ LECYTHIDACEAE } \\
\hline Couratari pyramidata (Vell.) R. Knuth. & 17299 & 14,0 & 7 & 7 & 0,038 & 0,38 \\
\hline \multicolumn{7}{|l|}{ MALPIGHIACEAE } \\
\hline Byrsonima myrcifolia Griseb. & 17300 & 25,0 & 4 & 4 & 0,359 & 1,19 \\
\hline B. stipulacea A. Juss. & 17301 & 15,0 & 7 & 5 & 0,105 & 0,57 \\
\hline \multicolumn{7}{|l|}{ MALVACEAE } \\
\hline Pseudobombax grandiflorum (Cav.) A. Robyns & 17302 & & Flora & & & \\
\hline \multicolumn{7}{|l|}{ MELASTOMATACEAE } \\
\hline Huberia laurina DC. & 17303 & 23,0 & 38 & 13 & 1,371 & 5,44 \\
\hline Leandra scabra DC. & 12239 & & Flora & & & \\
\hline Meriania claussenii Triana & 17304 & 8,0 & 1 & 1 & 0,011 & 0,07 \\
\hline Miconia brunnea Mart. & 17305 & & Flora & & & \\
\hline M. chartacea Triana & 15439 & 10,0 & 12 & 9 & 0,061 & 0,64 \\
\hline M. cinerascens Miq. & 17306 & & Flora & & & \\
\hline
\end{tabular}


Tabela 2 (continuação)

Famílias/Espécies

$\operatorname{Rg}$

MELASTOMATACEAE

Miconia cinnamomifolia (DC.) Naudin

M. cubatanensis Hoehne

M. eichlerii Cogn.

M. fasciculata Gardner

M. latecrenata (DC.) Naudin

M. minutiflora (Bonpl.) Triana

M. pusilliflora (DC.) Triana

M.sellowiana Naudin

M. urophylla DC.

Tibouchina arborea (Gardner) Cogn.

T. moricandiana

T. mutabilis Cogn.

T. pulchra Cogn.

T. sellowiana Cogn.

MELIACEAE

Cabralea canjerana (Vell.) Mart.

Cedrela fissilis Vell.

C. odorata $\mathrm{L}$.

Guarea kunthiana A. Juss.

MONIMIACEAE

Mollinedia engleriana Perkins

M. longifolia Tul.

M. triflora (Sprengel) Tul.

MORACEAE

Ficus luschnathiana (Miq.) Miq.

F. mexiae Standley

Sorocea bonplandii (Baillon) W. Burger

MYRISTICACEAE

Virola bicuhyba (Schott) Warb.

MYRSINACEAE

Myrsine coriacea (Swartz) R. Br.

M. gardneriana A. DC.

M. lancifolia Mart.

M. umbellata Mart.

M. venosa Mez

MYRTACEAE

Blepharocalyx salicifolius (Kunth) O. Berg

Calyptranthes brasiliensis Sprengel

C. grandifolia O. Berg

Campomanesia eugenioides (Cambess.) D. Legrand

Eugenia excelsa Cambess.

E. handroana D. Legrand

E. involucrata DC.

E. neoglomerata Sobral

E. subavenia O. Berg

Marlierea racemosa (Vell.) Kiaersk.

Myrcia breviramis (O. Berg) D. Legrand

$M$. eriopus DC.

M. fallax (Rich.) DC.

$M$. laruotteana Cambess.

M. variabilis DC.

Myrciaria floribunda (West) O. Berg

M. tenella (DC.) O.Berg

Plinia cauliflora (Mart.) Kausel

Siphoneugena densiflora O. Berg

S. widgreniana $\mathrm{O}$. Berg

$\mathrm{h}$

$\mathrm{N} \quad \mathrm{P}$

$\mathrm{P}$

AB

$\left(\mathrm{m}^{2}\right)$

(m)

VC

16,0

17308

17309

15100

17310

15434

17311

17312

17313

17314

10663

17315

17316

16258

16259

16870

15430

15690

17317

17318

17319

17320

16260

17321

12457

16262

17322

17323

15257

17324

17325

14961

17326

17327

17328

17330

17269

17331

17332

17333

17334

17335

17336

17337

17338

16279

17340

17339

16283

17341

10,0

10,5

15,0

10,0

11,0

12,0

10,0

21,0

13,0

14,0

5,0

6,0

9,0

11,5

11,0

12,5

8,5

\section{8,5}

15,0

10,0

14,5

12,0

6,5

10,0

5,0

14,0

16,0

5,0

7,0

14,0

11,5

25,0

20,0

12,5

5
Flora

10

0,584

0,027

3,40

Flora

Flora

10
Flora

7

5

28

8

Flora

1
106

Flora

50

3

3
1

1
1

1

1
25

Flora

$\begin{array}{lll}6 & 0,042 & 0,5 \\ 3 & 0,042 & 0,38\end{array}$

0,51

5

0,035

0,39

0,30

1,46

5

0,128

0,084

0,55

1

21

0,007

2,377

0,06

10,99

1

1
4
3

19
2
1
1

0,317

0,044

0,004

0,003

2,86

0,24

0,05

0,05

0,05

1,49

Flora

\section{1}

3
4

70

4

1

0,004

0,180

0,003

0,053

0,020

0,05

0,31

0,17

2
2

\author{
(a)
}

0,008

0,028

0,023

0,537

0,051

0,06

0,20

0,22

4,27

0,30

0,008

0,10

2

2

0,009

0,06

Flora

8

9

8
Flora

Flora

1

2

Flora

25

60

Flora

Flora

Flora

Flora

Flora 
Tabela 2 (continuação)

\begin{tabular}{|c|c|c|c|c|c|c|}
\hline Famílias/Espécies & $\mathrm{Rg}$ & $\begin{array}{c}\mathrm{h} \\
(\mathrm{m})\end{array}$ & $\mathrm{N}$ & $\mathrm{P}$ & $\begin{array}{l}\mathrm{AB} \\
\left(\mathrm{m}^{2}\right)\end{array}$ & $\mathrm{VC}$ \\
\hline \multicolumn{7}{|l|}{ NYCTAGINACEAE } \\
\hline Guapira opposita (Vell.) Reitz & 16284 & 13,5 & 30 & 12 & 0,258 & 1,91 \\
\hline \multicolumn{7}{|l|}{ OCHNACEAE } \\
\hline Ouratea parviflora Baillon & 17342 & 9,0 & 4 & 2 & 0,021 & 0,22 \\
\hline \multicolumn{7}{|l|}{ PICRAMNIACEAE } \\
\hline Picramnia glazioviana Engler & 17343 & & Flora & & & \\
\hline \multicolumn{7}{|l|}{ PIPERACEAE } \\
\hline Piper cernuum Vell. & 17344 & 4,5 & 1 & 1 & 0,005 & 0,05 \\
\hline P. crassinervium Kunth & 17345 & & Flora & & & \\
\hline P. dilatatum L.C. Rich & 17346 & 5,0 & 1 & 1 & 0,002 & 0,05 \\
\hline \multicolumn{7}{|l|}{ PODOCARPACEAE } \\
\hline Podocarpus lambertii Klotzsch & 17347 & & Flora & & & \\
\hline \multicolumn{7}{|l|}{ PROTEACEAE } \\
\hline Euplassa legalis (Vell.) Johnston & 17349 & 8,0 & 2 & 1 & 0,007 & 0,10 \\
\hline E. organensis (Gardner) Johnston & 17348 & 19,0 & 16 & 8 & 0,565 & 2,25 \\
\hline Roupala brasiliensis Klotzsch & 17042 & & Flora & & & \\
\hline \multicolumn{7}{|l|}{ ROSACEAE } \\
\hline Prunus myrtifolia (L.) Urban & 16291 & 15,0 & 26 & 10 & 0,159 & 1,47 \\
\hline \multicolumn{7}{|l|}{ RUBIACEAE } \\
\hline Amaioua guianensis Aublet & 12561 & 10,5 & 15 & 11 & 0,167 & 1,07 \\
\hline Bathysa australis (A. St.-Hil.) Hook. f. & 17352 & 9,0 & 6 & 2 & 0,020 & 0,29 \\
\hline Hillia parasitica Jacquin & 16293 & & Flora & & & \\
\hline Psychotria suterella Müll. Arg. & 17354 & 3,0 & 2 & 1 & 0,005 & 0,09 \\
\hline P. vellosiana Benth. & 17353 & 14,5 & 213 & 23 & 1,408 & 12,34 \\
\hline Rudgea jasminoides (Cham.) Müll. Arg. & 17355 & 5,0 & 2 & 1 & 0,008 & 0,10 \\
\hline$R$. recurva Müll. Arg. & 17356 & 7,5 & 1 & 1 & 0,005 & 0,05 \\
\hline \multicolumn{7}{|l|}{ RUTACEAE } \\
\hline Esenbeckia grandiflora Mart. & 17357 & 7,0 & 10 & 4 & 0,078 & 0,61 \\
\hline Pilocarpus pauciflorus A. St.-Hil. & 17358 & & Flora & & & \\
\hline Zanthoxylum rhoifolium Lam. & 12565 & 15,0 & 6 & 6 & 0,081 & 0,47 \\
\hline \multicolumn{7}{|l|}{ SABIACEAE } \\
\hline Meliosma brasiliensis Urban & 17359 & 8,5 & 2 & 2 & 0,054 & 0,23 \\
\hline M. sellowii Urban & 15476 & 11,5 & 3 & 3 & 0,074 & 0,33 \\
\hline \multicolumn{7}{|l|}{ SALICACEAE } \\
\hline Casearia arborea (L.C. Rich.) Urban & 17286 & 15,5 & 86 & 21 & 0,812 & 5,69 \\
\hline C. decandra Jacquin & 17287 & 12,5 & 26 & 15 & 0,155 & 1,46 \\
\hline C. mariquitensis Kunth & 17107 & & Flora & & & \\
\hline C. obliqua Sprengel & 15385 & 12,0 & 34 & 12 & 0,207 & 1,92 \\
\hline C. pauciflora Cambess. & 17288 & 20,0 & 22 & 10 & 0,332 & 1,81 \\
\hline Xylosma venosa N.E. Brown & 17289 & 4,5 & 1 & 1 & 0,002 & 0,05 \\
\hline \multicolumn{7}{|l|}{ SAPINDACEAE } \\
\hline Allophylus edulis (A. St.-Hil.) Radlk. & 17360 & 10,0 & 3 & 2 & 0,016 & 0,16 \\
\hline Cupania paniculata Cambess. & 15447 & & Flora & & & \\
\hline C. vernalis Cambess. & 14983 & & Flora & & & \\
\hline Matayba cristae Reitz & 15475 & & Flora & & & \\
\hline M. elaeagnoides Radlk. & 17049 & & Flora & & & \\
\hline Toulicia laevigata Radlk. & 17361 & 18,0 & 15 & 8 & 0,150 & 1,01 \\
\hline \multicolumn{7}{|l|}{ SAPOTACEAE } \\
\hline Chrysophyllum gonocarpum (Mart. \& Eichler) Engler & 17050 & 16,5 & 1 & 1 & 0,034 & 0,14 \\
\hline Pouteria caimito (Ruiz \& Pavón) Radlk. & 17362 & 18,5 & 3 & 2 & 0,192 & 0,67 \\
\hline P. guianensis Aublet & 17363 & & Flora & & & \\
\hline \multicolumn{7}{|l|}{ SOLANACEAE } \\
\hline Brugmansia suaveolens (Willd.) Bercht. \& J. Presl. & 17364 & & Flora & & & \\
\hline Cestrum corymbosum Schltdl. & 17365 & & Flora & & & \\
\hline C. schlechtendalii G. Don & 17366 & & Flora & & & \\
\hline Dyssochroma viridiflora (Sims) Miers & 17367 & 3,0 & 1 & 1 & 0,002 & $\begin{array}{r}0,04 \\
\text { continu }\end{array}$ \\
\hline
\end{tabular}


Tabela 2 (continuação)

\begin{tabular}{|c|c|c|c|c|c|c|}
\hline Famílias/Espécies & $\mathrm{Rg}$ & $\begin{array}{c}\mathrm{h} \\
(\mathrm{m})\end{array}$ & $\mathrm{N}$ & $\mathrm{P}$ & $\begin{array}{l}\text { AB } \\
\left(m^{2}\right)\end{array}$ & $\mathrm{VC}$ \\
\hline \multicolumn{7}{|l|}{ SOLANACEAE } \\
\hline Solanum bullatum Vell. & 17393 & 13,0 & 3 & 2 & 0,060 & 0,29 \\
\hline S. cinnamomeum Sendt. & 17368 & 14,0 & 21 & 9 & 0,313 & 1,72 \\
\hline S. granuloso-leprosum Dunal & 13040 & & Flora & & & \\
\hline S. lepidotum Dunal & 17392 & & Flora & & & \\
\hline S. leucodendron Sendt. & 16298 & & Flora & & & \\
\hline S. pseudoquina A. St.-Hil. & 17369 & 8,5 & 3 & 2 & 0,023 & 0,18 \\
\hline S. swartzianum Roem. \& Schult. & 17370 & 13,0 & 12 & 10 & 0,077 & 0,69 \\
\hline \multicolumn{7}{|l|}{ STYRACACEAE } \\
\hline Pamphilia aurea Mart. & 17371 & 20,0 & 4 & 2 & 0,055 & 0,31 \\
\hline \multicolumn{7}{|l|}{ SYMPLOCACEAE } \\
\hline Symplocos insignis Brand & 17372 & 5,0 & 1 & 1 & 0,004 & 0,05 \\
\hline \multicolumn{7}{|l|}{ THEACEAE } \\
\hline Gordonia fruticosa (Schrader) H. Keng. & 17373 & 16,0 & 20 & 4 & 0,218 & 1,41 \\
\hline \multicolumn{7}{|l|}{ THYMELAEACEAE } \\
\hline Daphnopsis fasciculata (Meisner) Nevling & 15466 & 17,0 & 12 & 7 & 0,110 & 0,78 \\
\hline \multicolumn{7}{|l|}{ URTICACEAE } \\
\hline Cecropia glaziovii Snethl. & 16403 & 13,5 & 2 & 2 & 0,103 & 0,38 \\
\hline C. hololeuca Miq. & 10290 & 19,0 & 12 & 6 & 0,258 & 1,21 \\
\hline Coussapoa microcarpa (Schott) Rizz. & 16235 & & Flora & & & \\
\hline \multicolumn{7}{|l|}{ VOCHYSIACEAE } \\
\hline Vochysia magnifica Warm. & 17375 & 22,0 & 183 & 24 & 2,878 & 15,43 \\
\hline \multicolumn{7}{|l|}{ WINTERACEAE } \\
\hline Drimys brasiliensis Miers & 17376 & 18,0 & 4 & 4 & 0,079 & 0,38 \\
\hline
\end{tabular}

Ilex e Cyathea (4), que juntos contribuíram com 32,1\% das espécies.

As comparações florísticas com outras 13 áreas de floresta inventariadas nas serras da Mantiqueira, do Mar e dos Órgãos são sumarizadas na Tabela 3. As maiores similaridades florísticas $\left(I_{s}>0,40\right)$ foram encontradas com quatro florestas interiores do complexo da Mantiqueira: Ibitipoca, Carrancas, Poço Bonito e Poços de Caldas. As exceções foram Tiradentes e Araponga, que aparecem nas posições $7^{\mathrm{a}}$ e $11^{\text {a }}$, apesar de sua situação geográfica interior. As sete áreas restantes estão situadas nas vertentes oceânicas das três serras, sendo que as duas áreas com maior dissimilaridade $\left(I_{s}<0,25\right)$, Camanducaia e

Tabela 3. Índices de similaridade florística de Sørensen $\left(I_{s}\right)$ entre a comunidade arbórea da Mata da Cachoeira do Rio Grande, Bocaina de Minas, MG, e as de outras 13 áreas de floresta inventariadas nas serras da Mantiqueira, do Mar e dos Órgãos (vide Fig. 1). As áreas estão relacionadas em ordem decrescente de $I_{s}$.

\begin{tabular}{|c|c|c|c|c|c|}
\hline \multirow[t]{2}{*}{ Áreas de floresta } & \multirow{2}{*}{$\begin{array}{c}\text { Altitude } \\
\text { mediana (m) }\end{array}$} & \multicolumn{2}{|c|}{ Número de espécies } & \multirow[t]{2}{*}{$I_{s}$} & \multirow[t]{2}{*}{ Fonte } \\
\hline & & Total & Em comum & & \\
\hline Ibitipoca & 1.450 & 234 & 117 & 0,560 & Fontes 1997 \\
\hline Carrancas & 1.480 & 200 & 102 & 0,531 & Oliveira-Filho et al. 2004 \\
\hline Poço Bonito & 1.115 & 356 & 120 & 0,444 & Dalanesi et al. 2004 \\
\hline Poços de Caldas & 1.450 & 197 & 77 & 0,404 & Fernandes 2003 \\
\hline Macaé de Cima & 1.200 & 338 & 103 & 0,395 & Lima \& Guedes-Bruni 1994 \\
\hline Serra da Cantareira & 1.100 & 214 & 73 & 0,367 & Baitello \& Aguiar 1982; Baitello et al. 1992 \\
\hline Tiradentes & 1.130 & 293 & 87 & 0,365 & Oliveira-Filho \& Machado 1993 \\
\hline Campos do Jordão & 1.750 & 176 & 59 & 0,328 & Robim et al. 1990 \\
\hline Atibaia & 1.180 & 166 & 54 & 0,309 & Meira Neto et al. 1989 \\
\hline Bananal & 1.208 & 106 & 44 & 0,303 & Castro 2001 \\
\hline Araponga & 1.410 & 96 & 39 & 0,279 & Ribeiro 2003 \\
\hline Camanducaia & 1.900 & 58 & 29 & 0,240 & França 2002 \\
\hline Itatiaia & 800 & 113 & 32 & 0,215 & Guedes-Bruni 1998 \\
\hline
\end{tabular}


Itatiaia, também constituem os extremos de maior e menor altitude, respectivamente.

Nas parcelas foram amostrados 2.574 indivíduos de 158 espécies, ou seja, 63 espécies $(28,5 \%)$ foram registradas fora das parcelas. Dez famílias contribuíram com $69,3 \%$ do número total de indivíduos, com Euphorbiaceae ocupando a primeira posição (12,8\%), seguida de Melastomataceae (10,3\%), Rubiaceae $(9,3 \%)$, Vochysiaceae $(7,1 \%)$, Salicaceae $(6,6 \%)$, Myrtaceae (5,6\%), Annonaceae (5,4\%), Cyatheaceae $(5,3 \%)$, Lauraceae $(3,8 \%)$ e Cunoniaceae $(3,3 \%)$. As dez espécies com maior densidade totalizaram $43,6 \%$ do número total de indivíduos, destacando-se Psychotria vellosiana (8,3\%), Vochysia magnifica $(7,1 \%)$, Alchornea triplinervia (6,4\%), Tibouchina pulchra (4,1\%), Casearia arborea (3,3\%), Lamanonia ternata $(3,3 \%)$, Guatteria pubens (3,1\%), Croton salutaris (3,0\%), Myrsine umbellata $(2,7 \%)$ e Myrcia fallax (3,3\%). Os dez maiores valores de área basal $(49,3 \%$ do total) foram registrados para as espécies Lamanonia ternata (8,7\%), Vochysia magnifica (8,3\%), Tibouchina pulchra (6,9\%), Alchornea triplinervia (5,4\%), Psychotria vellosiana $(4,1 \%)$, Huberia laurina $(4,0 \%)$, Hyptidendron asperrimum (3,5\%), Ocotea corymbosa $(3,4 \%)$, Tapirira obtusa $(2,8 \%)$ e Casearia arborea (2,3\%). Na estratificação da comunidade observa-se que um elevado número de espécies atinge estaturas elevadas: 18 delas registraram alturas máximas $\geq 20 \mathrm{~m}$.

O índice de diversidade de Shannon $\left(H^{\prime}\right)$ e o índice de equabilidade de Pielou $\left(J^{\prime}\right)$ para a amostra total foram de 4,15 nats.ind. ${ }^{-1}$ e 0,82 , respectivamente (Tab. 4). O valor de $H^{\prime}$ da subamostra dos Latossolos

Tabela 4. Diversidade de espécies da comunidade arbórea da Mata da Cachoeira do Rio Grande, Bocaina de Minas, MG: número de indivíduos (Ind) e de espécies (Spp), índice de diversidade de Shannon $\left(H^{\prime}\right)$ e equabilidade de Pielou $\left(J^{\prime}\right)$ na amostra total $(N=26$ parcelas de $20 \times 20 \mathrm{~m}$ ) e nas três classes de solo que a compõem. Para os Latossolos Vermelhos e Latossolos Vermelho-Amarelos, os valores foram calculados para uma subamostra aleatória de $N=6$ parcelas, para homogeneizar o tamanho da amostragem com base nos Latossolos Vermelhos $(N=6)$.

\begin{tabular}{lrrrrrr}
\hline Subgrupos de solos & $N$ & Ind & Spp $\frac{H^{\prime}}{\left.\text { (nats.ind. }{ }^{-1}\right)}$ & \\
& & & & \\
& 26 & 2574 & 159 & 4,15 & 0,82 \\
\hline Amostra total & 6 & 568 & 97 & 3,91 & 0,85 \\
Latossolos Amarelos (LAd) & 6 & 569 & 87 & 3,67 & 0,82 \\
Latossolos Vermelho-Amarelos & 6 & & & & \\
$\quad($ LVAd2) & 6 & 577 & 85 & 3,73 & 0,84 \\
Latossolos Vermelhos (LVd2) & & & &
\end{tabular}

Amarelos foi significativamente maior que os valores de $H^{\prime}$ das subamostras Latossolos Vermelho-Amarelos ( $t$ de Hutcheson $=3,36, P<0,001)$ e Latossolos Vermelhos ( $t$ de Hutcheson $=2,54, P<0,01)$. Contudo, os valores de $H$ ' das duas últimas classes de solo não diferiram significativamente entre si $(t$ de Hutcheson $=0,92, P>0,1)$. Como os valores de $J$ ' são muito próximos para as três classes de solo, o maior $H^{\prime}$ dos Latossolos Amarelos deve estar mais fortemente vinculado a uma maior riqueza de espécies por área.

As três classes de solos compartilharam muitas espécies entre as mais abundantes. As cinco espécies com maior VC nos Latossolos Amarelos foram Vochysia magnifica, Tibouchina pulchra, Psychotria vellosiana, Alchornea triplinervia e Myrsine umbellata; nos Latossolos Vermelho-Amarelos foram Psychotria vellosiana, Alchornea triplinervia, Lamanonia ternata, Vochysia magnifica e Huberia laurina; e nos Latossolos Vermelhos foram Lamanonia ternata, Tibouchina pulchra, Alchornea triplinervia, Croton salutaris e Psychotria vellosiana (Tab. 5). Observa-se que Psychotria vellosiana e Alchornea triplinervia repetem-se nesta posição nas três classes de solo, enquanto Vochysia magnifica, Tibouchina pulchra e Lamanonia ternata repetem-se em duas classes de solo. Apenas Myrsine umbellata, Huberia laurina e Croton salutaris foram exclusivas de uma das três classes de solo nestas cinco posições de VC, mas ocorreram em todas elas em menor abundância.

Os 2.574 indivíduos com $\mathrm{DAP} \geq 5 \mathrm{~cm}$ inventariados na amostra (1,2ha) somaram uma área basal de $34,60 \mathrm{~m}^{2}$. As três classes de solo não diferiram significativamente entre si tanto para a densidade de indivíduos $(F=0,11, P=0,89)$ como para a área basal $(F=0,19, P=0,83$ ) (Tab. 6). No entanto, houve diferença significativa entre os Latossolos Amarelos e os demais tipos de solos em termos da distribuição dos indivíduos por classes de diâmetro (Tab. 7). Os Latossolos Amarelos apresentaram menos indivíduos de pequeno porte (DAP > 5 a $10 \mathrm{~cm},>10$ a $20 \mathrm{~cm}$ ) e mais indivíduos com DAP $>20$ a $40 \mathrm{~cm}$ que o esperado se sua distribuição por classe de diâmetro fosse igual a dos outros Latossolos (Fig. 3A). Já os Latossolos Vermelho-Amarelos e Latossolos Vermelhos apresentaram distribuições de indivíduos por classes de diâmetro semelhantes entre si. Em termos da distribuição de indivíduos por classes de altura, todas as classes de solo diferiram entre si (Fig. 3B, Tab. 8). $\mathrm{Na}$ seqüência, Latossolos Amarelos - Latossolos Vermelho-Amarelos - Latossolos Vermelhos, houve 
Tabela 5. Relação das 49 espécies arbóreas mais abundantes (VC > 1) na amostra de 26 parcelas de 20×20m utilizadas para inventariar a Mata da Cachoeira do Rio Grande, em Bocaina de Minas, MG, seguidas da abreviação utilizada na análise de correspondência canônica (Fig. 4) e do valor de cobertura obtidos na amostra total e nas subamostras correspondentes às três classes de solo: LAd = Latossolos Amarelos; LVAd2 = Latossolos Vermelho-Amarelos; LVd2 = Latossolos Vermelhos. Espécies em ordem decrescente de VC na amostra total.

\begin{tabular}{|c|c|c|c|c|c|}
\hline \multirow[t]{2}{*}{ Espécies } & \multirow[t]{2}{*}{ Abreviações } & \multicolumn{4}{|c|}{ Valor de Cobertura (VC) } \\
\hline & & Total & LAd & LVAd2 & $\mathrm{LVd} 2$ \\
\hline Vochysia magnifica & Voch mag & 15,43 & 23,69 & 11,57 & 3,87 \\
\hline Psychotria vellosiana & Psyc vel & 12,34 & 8,66 & 21,04 & 7,96 \\
\hline Lamanonia ternata & Lama ter & 11,96 & 5,27 & 15,47 & 20,51 \\
\hline Alchornea triplinervia & Alch tri & 11,75 & 6,59 & 15,97 & 16,56 \\
\hline Tibouchina pulchra & Tibo pul & 10,99 & 10,66 & 7,11 & 17,07 \\
\hline Casearia arborea & Case arb & 5,69 & 4,27 & 7,16 & 6,57 \\
\hline Huberia laurina & Hube lau & 5,44 & 6,27 & 8,03 & 0,23 \\
\hline Ocotea corymbosa & Ocot cor & 4,90 & 3,53 & 6,45 & 5,49 \\
\hline Guatteria pubens & Guat pub & 4,63 & 3,60 & 6,46 & 4,27 \\
\hline Hyptidendron asperrimum & Hypt asp & 4,57 & 2,76 & 7,38 & 4,29 \\
\hline Vernonanthura diffusa & Vern dif & 4,55 & 6,18 & 4,10 & 1,83 \\
\hline Croton salutaris & Crot sal & 4,31 & 4,26 & 0,31 & 9,96 \\
\hline Myrsine umbellata & Myrs umb & 4,27 & 6,54 & 2,52 & 2,02 \\
\hline Myrciafallax & Myrc fal & 3,93 & 4,76 & 3,10 & 3,41 \\
\hline Cyathea corcovadensis & Cyat cor & 3,83 & 2,31 & 8,01 & 1,16 \\
\hline Tapirira obtusa & Tapi obt & 3,77 & 2,57 & 7,15 & 1,43 \\
\hline Miconia cinnamomifolia & Mico cin & 3,40 & 3,32 & 1,40 & 6,38 \\
\hline Cyathea delgadii & Cyat del & 3,35 & 4,49 & 3,73 & 0,47 \\
\hline Cabralea canjerana & Cabr can & 2,86 & 3,19 & 3,10 & 1,85 \\
\hline Alchornea sidifolia & Alch sid & 2,83 & 6,05 & 0,00 & 0,22 \\
\hline Clethra scabra & Clet sca & 2,64 & 5,18 & 0,42 & 0,53 \\
\hline Euplassa organensis & Eupl org & 2,25 & 1,13 & 0,53 & 6,94 \\
\hline Vernonanthura discolor & Vern dis & 2,24 & 1,54 & 1,59 & 4,59 \\
\hline Tetrorchidium parvulum & Tetr par & 2,08 & 3,76 & 0,75 & 0,47 \\
\hline Casearia obliqua & Case obl & 1,92 & 3,79 & 0,51 & 0,00 \\
\hline Guapira opposita & Guap opp & 1,91 & 3,72 & 0,18 & 0,58 \\
\hline Casearia pauciflora & Case pau & 1,81 & 0,21 & 2,58 & 4,04 \\
\hline Solanum cinnamomeum & Sola cin & 1,72 & 3,15 & 0,68 & 0,22 \\
\hline Poeppigia procera & Poep pro & 1,67 & 0,00 & 2,60 & 3,86 \\
\hline Sclerolobium rugosum & Scle rug & 1,65 & 0,00 & 2,10 & 4,45 \\
\hline Persea major & Pers maj & 1,65 & 2,83 & 1,12 & 0,00 \\
\hline Mollinedia longifolia & Moll lon & 1,49 & 2,77 & 0,00 & 0,91 \\
\hline Prunus myrtifolia & Prun myr & 1,47 & 3,00 & 0,24 & 0,00 \\
\hline Schefflera longepetiolata & Sche lon & 1,47 & 1,17 & 1,77 & 1,66 \\
\hline Casearia decandra & Case dec & 1,46 & 1,50 & 0,78 & 2,33 \\
\hline Miconia urophylla & Mico uro & 1,46 & 0,13 & 2,89 & 2,24 \\
\hline Siphoneugena densiflora & Siph den & 1,44 & 0,62 & 0,54 & 4,40 \\
\hline Pera glabrata & Pera gla & 1,44 & 1,35 & 2,25 & 0,49 \\
\hline Gordonia fruticosa & Gord fru & 1,41 & 0,00 & 0,16 & 6,04 \\
\hline Myrcia eriopus & Myrc eri & 1,39 & 0,66 & 2,94 & 0,77 \\
\hline Dalbergia villosa & Dalb vil & 1,25 & 0,47 & 1,52 & 2,48 \\
\hline Nectandra oppositifolia & Nect opp & 1,24 & 1,72 & 0,58 & 1,17 \\
\hline Cecropia hololeuca & Cecr hol & 1,21 & 1,70 & 0,59 & 1,08 \\
\hline Byrsonima myrcifolia & Byrs myr & 1,19 & 0,12 & 0,22 & 4,73 \\
\hline Alsophila setosa & Also set & 1,16 & 2,50 & 0,00 & 0,00 \\
\hline Senna macranthera & Senn mac & 1,14 & 1,50 & 0,71 & 1,01 \\
\hline Amaioua guianensis & Amai gui & 1,07 & 1,35 & 1,07 & 0,48 \\
\hline Aspidosperma spruceanum & Aspi spr & 1,06 & 0,13 & 0,39 & 3,88 \\
\hline Toulicia laevigata & Toul lae & 1,01 & 0,11 & 1,86 & 1,71 \\
\hline
\end{tabular}


Tabela 6. Densidade e área basal de árvores (DAP $\geq 5 \mathrm{~cm}$ ) por hectare nas 26 parcelas de $20 \times 20 \mathrm{~m}$ utilizadas para amostrar a Mata da Cachoeira do Rio Grande, em Bocaina de Minas, MG. Os valores são médias \pm desvios padrão da amostra total e das $N$ parcelas das três classes de solo.

\begin{tabular}{lrcc}
\hline Classes de solos & $N$ & $\begin{array}{c}\text { Densidade } \\
(\text { árvores.ha }\end{array}$ & $\begin{array}{c}\text { Área basal } \\
\left(\mathrm{m}^{2} \cdot \mathrm{ha}^{-1}\right)\end{array}$ \\
\hline $\begin{array}{l}\text { Amostra total } \\
\text { Latossolos Amarelos (LAd) }\end{array}$ & 26 & $2.475 \pm 472$ & $33,27 \pm 7,02$ \\
$\begin{array}{l}\text { Latossolos Vermelho-Amarelos } \\
\quad \text { (LVAd2) }\end{array}$ & $2.519 \pm 390$ & $32,76 \pm 7,72$ \\
$\begin{array}{l}\text { Latossolos Vermelhos (LVd2) } \\
\text { (L) }\end{array}$ & 6 & $2.404 \pm 505$ & $32,55 \pm 6,56$ \\
\hline
\end{tabular}

um aumento significativo dos indivíduos de menor porte e diminuição do número de indivíduos de maior altura. Distribuição das espécies - Os autovalores da CCA para os três primeiros eixos de ordenação foram de 0,291 (eixo 1), 0,094 (eixo 2) e 0,067 (eixo 3). O primeiro autovalor pode ser considerado baixo $(<0,5$ sensu ter Braak 1995), indicando a existência de um gradiente curto no primeiro eixo, ou seja, com poucas substituições de espécies entre os dois extremos e predominância da variação nas abundâncias das espécies. Os outros dois eixos têm autovalores muito baixos e, portanto, desconsideráveis. Os três primeiros eixos explicaram apenas 14,7\% (eixo 1) e 4,8\% (eixo 2) e 3,4\% (eixo 3) da variância global dos dados (total acumulado: 22,8\%), indicando muito 'ruído', ou variância remanescente não explicada pelas variáveis ambientais empregadas. No entanto, 'ruído' elevado constitui uma característica comum em dados de vegetação e isto não prejudica o significância das relações espécie-ambiente (ter Braak 1987). De fato, o primeiro eixo de ordenação produziu uma alta correlação espécie-ambiente de 0,865 e o teste de permutação de Monte Carlo indicou que as abundâncias das espécies e as variáveis ambientais foram significativamente correlacionadas neste eixo
$(P=0,01)$. Os eixos 2 e 3 produziram correlações mais baixas, 0,631 e 0,569, e não significativas pelo teste de Monte Carlo. As variáveis ambientais mais fortemente correlacionadas com o primeiro eixo foram, em ordem decrescente, cota, matéria orgânica e teores de areia e argila (Tab. 9). As correlações ponderadas mostraram também interrelações fortes entre as quatro variáveis, destacando-se as correlações entre a cota e matéria orgânica e entre cota e areia, ambas positivas, e entre
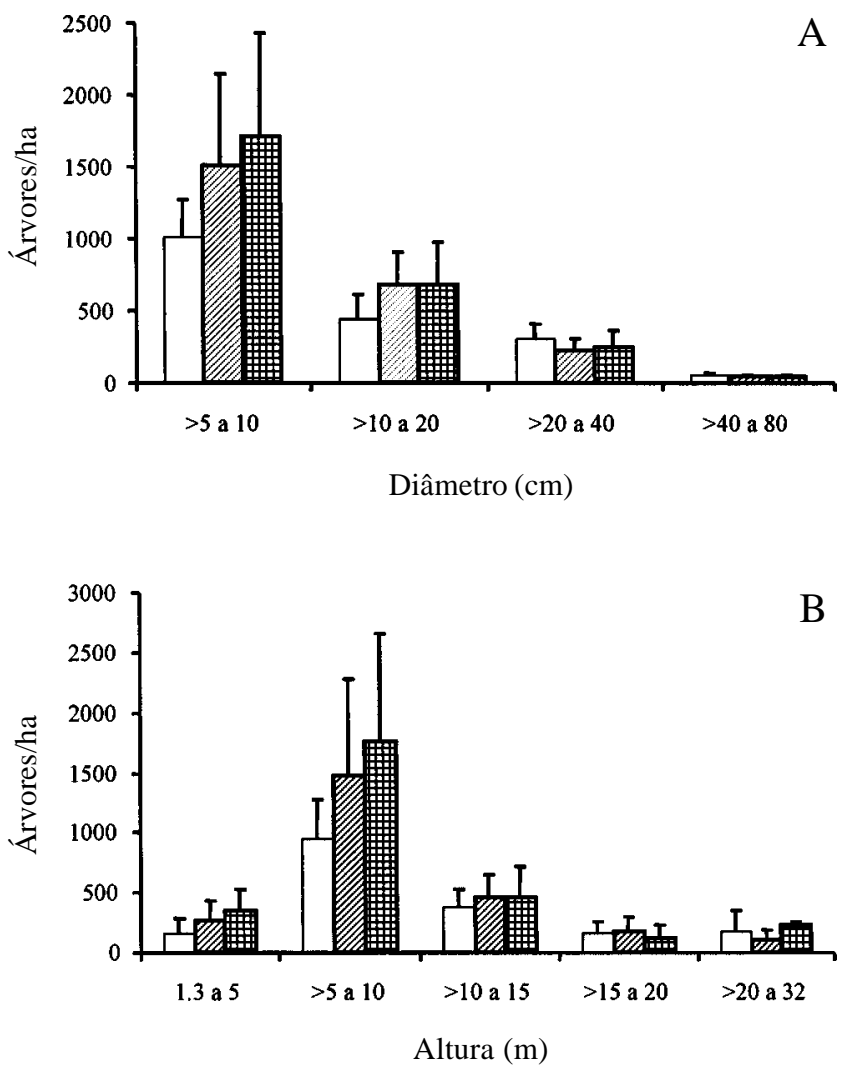

Figura 3. Distribuição da densidade por hectare de árvores com DAP maior ou igual a $5 \mathrm{~cm}$ em classes de diâmetro (A) e altura (B) nas parcelas utilizadas para amostrar a Mata da Cachoeira do Rio Grande, Bocaina de Minas, MG, agrupadas nas três classes de

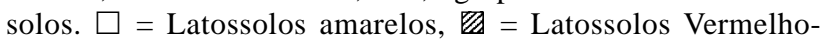
Amarelos, = Latossolos Vermelhos.

Tabela 7. Comparação entre as distribuições do número de indivíduos por classes de DAP (diâmetro a altura do peito) entre os três diferentes tipos de solos encontrados na área de estudos. São apresentados os valores do teste $\chi^{2}$ acompanhados das suas respectivas probabilidades (entre parênteses). As distribuições por classes de DAP podem ser visualizadas na Figura 3.

\begin{tabular}{llccc}
\hline & & & Base da distribuição esperada \\
\cline { 3 - 5 } & & LAd & LVAd & LVd \\
\hline Distribuição observada & LAd & - & $59,7(P<0,00001)$ & $64,6(P<0,00001)$ \\
& LVAd & $33,2(P<0,0001)$ & - & $3,0(P<0,38978)$ \\
& LVd & $29,9(P<0,0001)$ & $2,3(P<0,50613)$ & - \\
\hline
\end{tabular}


Tabela 8. Comparação entre as distribuições do número de indivíduos por classes de altura entre os três diferentes tipos de solo encontrados na área de estudos. São apresentados os valores do teste $\chi^{2}$ acompanhados das suas respectivas probabilidades (entre parênteses). As distribuições por classes de altura podem ser visualizadas na Figura 3.

\begin{tabular}{llccc}
\hline & & & Base da distribuição esperada \\
\cline { 3 - 5 } & & LAd & LVAd & LVd \\
\hline Distribuição observada & LAd & - & $65,8(P<0,00001)$ & $186,3(P<0,00001)$ \\
& LVAd & $39,5(P<0,00001)$ & - & $29,2(P<0,00001)$ \\
& LVd & $85,6(P<0,00001)$ & $18,9(P<0,00084)$ & - \\
\hline
\end{tabular}

Tabela 9. Análise de correspondência canônica (CCA): correlações internas ( 'intraset') nos dois primeiros eixos de ordenação e matriz de correlações ponderadas para as variáveis ambientais utilizadas na análise. Correlações com valores absolutos > 0.5 estão indicadas em negrito.

\begin{tabular}{|c|c|c|c|c|c|c|}
\hline \multirow[t]{2}{*}{ Variáveis ambientais } & \multicolumn{2}{|c|}{ Correlações ponderadas } & \multirow[t]{2}{*}{ Matéria orgânica } & \multirow[t]{2}{*}{ Argila } & \multirow[t]{2}{*}{ Areia } & \multirow[t]{2}{*}{ Cota } \\
\hline & Eixo 1 & Eixo 2 & & & & \\
\hline Matéria orgânica & 0,622 & $-0,601$ & - & & & \\
\hline Argila & $-0,551$ & $-0,107$ & $-0,435$ & - & & \\
\hline Areia & $\mathbf{0 , 5 5 1}$ & 0,277 & $\mathbf{0 , 5 2 7}$ & $-0,800$ & - & \\
\hline Cota & 0,991 & $-0,129$ & 0,695 & $-0,520$ & 0,496 & - \\
\hline
\end{tabular}

cota e argila e entre argila e teor de areia, ambas negativas.

A ordenação das parcelas no primeiro eixo (Fig. 4A) sugeriu claramente um forte gradiente catenário dos Latossolos Amarelos para os Latossolos Vermelho-Amarelos e destes para os Latossolos Vermelhos. Um exame da identidade das parcelas permitiu ainda perceber que os alinhamentos amostrais se sucedem no mesmo gradiente com muita clareza, indo de $\mathrm{A}$ até $\mathrm{F}$, o que sugeriu a preponderância de um gradiente de elevação topográfica. Este fato é confirmado pela maior correlação com a variável cota. As variáveis areia, argila e matéria orgânica covariaram com a elevação topográfica.

A ordenação das espécies pela CCA (Fig. 4B) sugeriu que espécies como Alchornea sidifolia, Guapira opposita, Casearia obliqua, Alsophila setosa, Clethra scabra, Prunus myrtifolia e Mollinedia longifolia tenderam a ser mais abundantes nos Latossolos Amarelos na baixa encosta e espécies como Gordonia fruticosa, Sclerolobium rugosum, Miconia urophylla, Siphoneugena densiflora, Toulicia laevigata, Poeppigia procera, Dalbergia villosa e Byrsonima myrcifolia tenderam a ser mais abundantes nos Latossolos Vermelhos da alta encosta. Contudo, a maioria das espécies, como as 18 do aglomerado central, ficou distribuída de forma mais homogênea no gradiente ou foram mais abundantes nos Latossolos Vermelho-Amarelos da meia encosta.

\section{Discussão}

Perfil e contexto florístico - A influência da altitude na diferenciação florística das florestas do estado de São Paulo foi demonstrada para florestas semidecíduas por Salis et al. (1995) e ombrófilas, por Scudeller et al. (2001) e Ivanauskas \& Rodrigues (2000), padrões estes descritos para o Sudeste brasileiro por Oliveira-Filho $\&$ Fontes (2000). A Mata de Bocaina apresentou características florísticas reconhecidas como indicadoras de florestas de maiores altitudes do Sudeste do Brasil ou mesmo dos Neotrópicos. Por exemplo, a menor riqueza relativa de espécies de Fabaceae e a maior riqueza de espécies de Lauraceae, Asteraceae, Cyatheaceae, Solanaceae, Melastomataceae, Myrsinaceae e Aquifoliaceae correspondem ao perfil florístico descrito por Oliveira-Filho \& Fontes (2000) para as Florestas Atlânticas Alto-montanas, tanto ombrófilas como semidecíduas. Gentry (1995), analisando florestas Andinas e da América Central, também observou a perda de importância da família Fabaceae a partir dos $1.500 \mathrm{~m}$ de altitude, enquanto aumenta o predomínio de Lauraceae, Melastomataceae e Rubiaceae. Além disso, as famílias mais ricas na Mata de Bocaina, Melastomataceae e Myrtaceae, 
também são consideradas por Webster (1995) como características de florestas nebulares dos Neotrópicos, além de outras aí encontradas como Aquifoliaceae, Clethraceae, Clusiaceae, Cunoniaceae, Elaeocar-

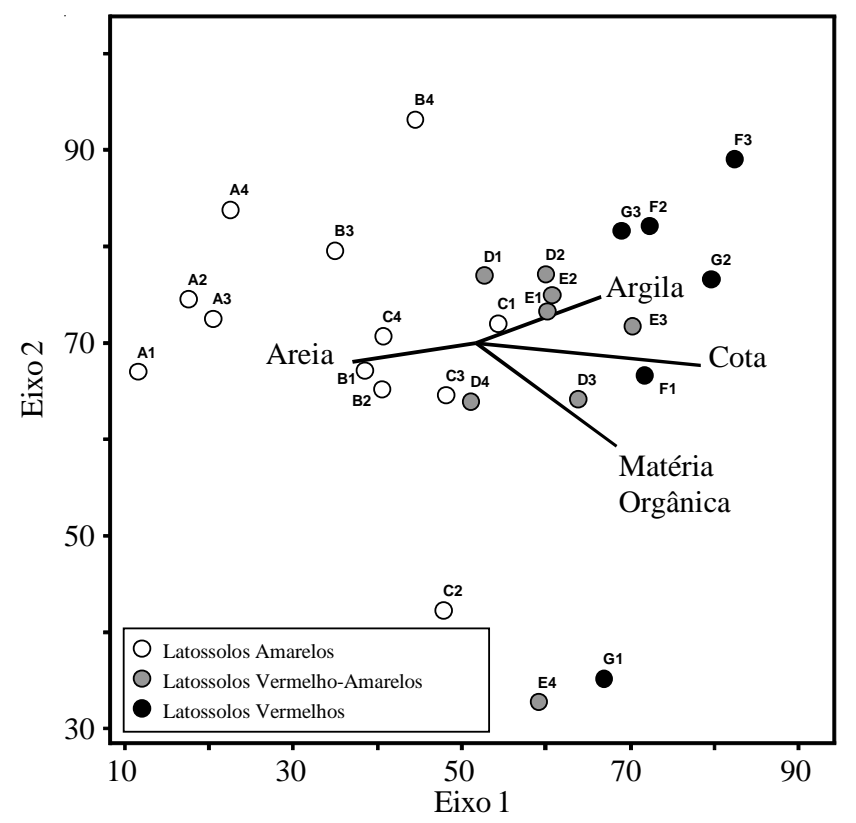

B

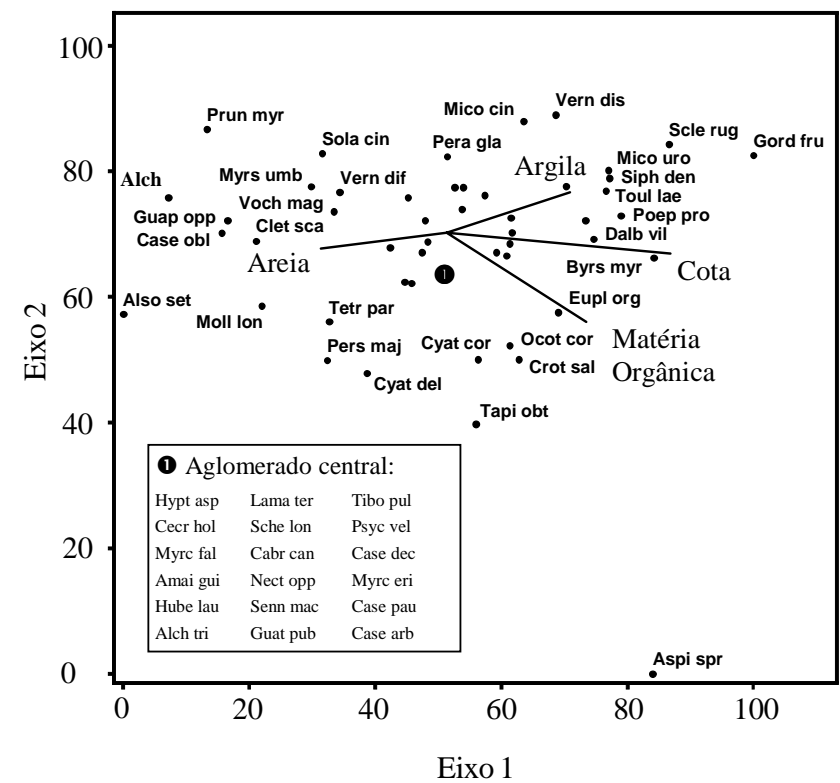

Figura 4. Análise de correspondência canônica: diagrama de ordenação das parcelas (A) e espécies (B) baseada na distribuição do número de indivíduos de 49 espécies em 26 parcelas utilizadas para amostrar a Mata da Cachoeira do Rio Grande, Bocaina de Minas, MG, e sua correlação com as quatro variáveis ambientais utilizadas (retas). As parcelas são identificadas conforme a fig. 2B e classificadas nas três classes de solos. As espécies são indicadas pelo seu nome abreviado (correspondência com nomes completos na Tab. 5). paceae, Podocarpaceae, Rosaceae, Sabiaceae, Styracaceae, Symplocaceae e Winteraceae. Entre os gêneros mais ricos em espécies encontrados na Mata de Bocaina, Miconia e Ilex são também considerados pelo autor como característicos das florestas nebulares, além de outros que aí ocorreram, como Cyathea, Clethra, Clusia, Drimys, Ficus, Meliosma, Podocarpus, Prunus e Roupala.

Das 65 espécies apontadas Oliveira-Filho \& Fontes (2000) como indicadoras de Florestas Atlânticas Alto-montanas, 31 (ou 48\%) ocorreram na Mata de Bocaina. São elas Casearia obliqua, Cecropia glaziovii, Cinnamomum glaziovii, Clethra scabra, Clusia criuva, Daphnopsis fasciculata, Drimys brasiliensis, Ficus luschnatiana, F. mexiae Geonoma schottiana, Gordonia fruticosa, Guatteria nigrescens, Hedyosmum brasiliensis, Maytenus glazioviana, M. salicifolia, Meliosma sellowii, Miconia brunnea, M. chartacea, M. cinnamomifolia, Myrcia laruotteana, Myrsine lancifolia, Nectandra grandiflora, N. lanceolata, N. puberula, Picramnia glazioviana, Psychotria suterella, Siphoneugena widgreniana, Solanum bullatum, Tabebuia chrysotricha e Vismia brasiliensis. Espécies indicadoras de outras formações florestais apontadas por Oliveira-Filho e Fontes (2000) apareceram na Mata de Bocaina em número bastante reduzido. A Mata de Bocaina ainda apresenta uma peculiaridade fisionômica citada por Gentry (1995) como característica das florestas alto-montanas neotropicais, que é a abundância de epífitas, sobretudo de bromélias, orquídeas, pteridófitas, musgos e líquens.

Numa análise comparativa incluindo outras florestas de maiores altitudes da região, o perfil florístico da comunidade arbórea da Mata de Bocaina mostra uma maior proximidade com outras florestas alto-montanas do interior da Mantiqueira em seu trecho meridional, o que inclui as áreas de Ibitipoca, Carrancas, Poços de Caldas e Poço Bonito. As duas outras florestas interiores da Mantiqueira, Tiradentes e Araponga, provavelmente diferenciam-se mais da Mata de Bocaina por estarem em regiões com estação seca mais pronunciada (> 40 dias de déficit em diagramas de Walter). É importante notar que áreas geograficamente próximas, como Itatiaia, Bananal, Camanducaia e Campos do Jordão, produziram menor similaridade com a Mata de Bocaina, o que é explicado, provavelmente, pelas altitudes mais elevadas de Camanducaia e Campos do Jordão, pela menor altitude de Itatiaia e pela maior pluviosidade de Bananal. 
Diversidade, estrutura e distribuição das espécies - O número de espécies encontrado na Mata de Bocaina (221) pode ser considerado intermediário quando comparado com o das outras 13 florestas comparadas. Os índices de Shannon (4,15 nats.ind. $\left.{ }^{-1}\right)$ e de equabilidade de Pielou $(0,82)$ encontrados, também apresentam-se intermediários entre os mesmos levantamentos consultados. $\mathrm{Na}$ análise da variação local da diversidade, o setor do Latossolo Amarelo, que apresentou o maior valor, corresponde à faixa da floresta mais próxima ao rio onde o terreno tende a ser moderadamente drenado. Geralmente, as faixas de vegetação ciliar apresentam grande heterogeneidade ambiental, em consequiência de fatores bióticos e abióticos, que resultam em manchas de vegetação com diferentes características florísticas e estruturais, podendo contribuir para uma maior diversidade local (Rodrigues 2000). O setor do Latossolo VermelhoAmarelo, onde foi encontrada a menor diversidade de espécies, corresponde ao interior da floresta, área de meia encosta, onde o solo é bem a acentuadamente drenado. A maior declividade nas parcelas de meia encosta, a presença de uma trilha na parcela E2 e a presença de grande quantidade de bambus nas parcelas F2, G1, G2 e G3 provavelmente contribuíram para a diminuição da diversidade, muito embora vários atributos de solos sejam melhores neste setor. É conhecido que a ocorrência de alta densidade de bambus em florestas, reduz o recrutamento e o crescimento de árvores, podendo reduzir localmente a diversidade (Oliveira-Filho et al. 1994c). Em situação intermediária de diversidade, o setor do Latossolo Vermelho, está localizado no topo da floresta, com solo acentuadamente drenado. Alguns estudos têm ressaltado que as áreas de amostragens que se encontram fora da influência de cursos d'água apresentam diferenças conspícuas daquelas diretamente influenciadas pelos mesmos (Metzger et al. 1997).

A densidade de árvores encontrada na Mata de Bocaina, de 2.475 árvores ha ${ }^{-1}$, situa-se entre as mais elevadas (segunda posição) registradas em 20 levantamentos realizados na região do Alto Rio Grande utilizando o mesmo diâmetro mínimo e que variam de 2.683 árvores ha ${ }^{-1}$, em Ingaí, a 969 árvores ha $^{-1}$, em Ibituruna (J.A.A. Pereira, dados não publicados). Quanto à área basal, que foi de $33,27 \mathrm{~m}^{2} \mathrm{ha}^{-1}$, a Mata de Bocaina também apresentou valores elevados em relação às outras áreas, ocupando a quinta posição de uma amplitude que variou de $42,37 \mathrm{~m}^{2} \mathrm{ha}^{-1}$, em Piedade do Rio Grande, a 19,79 $\mathrm{m}^{2} \mathrm{ha}^{-1}$, em Tiradentes (J.A.A.
Pereira, dados não publicados). Estes valores indicam densidade e biomassa relativamente elevadas em relação à maioria das matas da região. Diferenças entre estas florestas relacionadas ao histórico de distúrbios, efeito borda, estoque de nutrientes minerais e regime de água no solo podem estar vinculadas a estes padrões, o que requer estudos comparativos mais precisos para permitir inferências mais seguras. A redução do porte da floresta à medida que se sobe a encosta (seqüência Latossolos Amarelos - Latossolos Vermelho-Amarelos - Latossolos Vermelhos), refletido tanto na distribuição dos indivíduos por classes de diâmetro como por classes de altura, provavelmente está relacionada à redução da disponibilidade hídrica com o distanciamento do rio. Portanto, estas mudanças na estrutura vertical provavelmente não estão relacionadas à tendência de melhora das condições físicas e nutricionais dos solos à medida que se sobe a encosta. Se as mudanças estruturais estivessem relacionadas a isto, deveria esperar-se o resultado oposto, ou seja, o aumento do porte da vegetação com o distanciamento do rio.

A influência da umidade dos solos na distribuição de espécies arbóreas e nas variações fisionômicas nas florestas tropicais tem largo subsídio na literatura (por exemplo: Basnet 1992, Clark et al. 1998, Oliveira-Filho et al. 1994b, van den Berg \& Oliveira-Filho 1999, Botrel et al. 2002). Na Mata de Bocaina é muito clara, por exemplo, a maior abundância de Vochysia magnifica, Alchornea sidifolia, Casearia obliqua e Alsophila setosa nas proximidades do rio, de Psychotria vellosiana e Huberia laurina na meia encosta e de Lamanonia ternata, Alchornea triplinervia e Tibouchina pulchra no topo da floresta. A abundância, no topo da floresta, de bambus e de Alchornea triplinervia, espécie típica de ambientes recentemente colonizados (F.A.B. Fernandes, dados não publicados), parecem indicar a possibilidade da ocorrência ali, de atividades antrópicas, como fogo e/ ou desmatamento, comuns naquela região, principalmente em épocas passadas. A despeito do presente trabalho haver detectado uma clara correlação entre a distribuição de espécies e as características do substrato, com ênfase para a disponibilidade de água nos solos, foi também identificado um razoável montante de variância não explicada pelas variáveis ambientais fornecidas (o 'ruído'). O histórico de perturbação diferenciada é uma possível variável não considerada e de difícil controle. Se perturbações naturais promovidas pelo processo de silvigênese podem criar um mosaico de eco-unidades de variada 
composição e estrutura (Oldeman 1983), aquelas promovidas pelo homem e pelo gado constituem um fator adicional a ser considerado na área de estudos (Toniato \& Oliveira-Filho 2004). Acrescente-se a isto que ainda se pode deixar uma larga margem para efeitos estocásticos na distribuição das espécies. Desta forma, é necessário ter em mente que correlações detectadas entre a distribuição de espécies e variáveis do substrato, ainda que verdadeiras, sempre refletem um pequeno fragmento da realidade.

\section{Agradecimentos}

Agradecemos à proprietária da área, Sra. Maria por permitir a realização deste estudo; ao aluno da UFLA,Vagner Fernandes Silva, pelo auxílio nos trabalhos de campo.

\section{Referências bibliográficas}

APG II. 2003. An update of the Angiosperm Phylogeny Group classification for the orders and families of flowering plants: APG II. Botanical Journal of the Linnaean Society 141: 399-436.

Baitello, J.B. \& Aguiar, O.T. 1982. Flora arbórea da Serra da Cantareira. Anais do I Congresso Nacional sobre Essências Nativas. Silvicultura em São Paulo 16A: 582-646.

Baitello, J.B.; Aguiar, O.T.; Rocha, F.T.; Pastore, J.A. \& Esteves, R. 1992. Florística e fitossociologia do estrato arbóreo de um trecho da Serra da Cantareira (Núcleo Pinheirinho), SP. Anais do II Congresso Nacional sobre Essências Nativas. Revista do Instituto Florestal de São Paulo 4: 291-297.

Barros, W.D. 1948. Floresta protetora na região do Itatiaia. Revista Florestal 7: 20-23.

Barros, W.D. 1955. Parque Nacional do Itatiaia. Rio de Janeiro, IBGE.

Barros, W.D. 1958. O Parque Nacional de Itatiaia. Anuário Brasileiro de Economia Florestal 10: 318-337.

Barros, W.D. 1959. O revestimento vegetal do Parque Nacional do Itatiaia. Anuário Brasileiro de Economia Florestal 11: 115-117.

Basnet, K. 1992. Effect of topography on the pattern of trees in tabonuco (Dacryodes excelsa) dominated rain forest of Puerto Rico. Biotropica 24: 31-42.

Botrel, R.T.; Oliveira-Filho, A.T.; Rodrigues, L.A. \& Curi, N. 2002. Influência do solo e topografia sobre as variações da composição florística e estrutura da comunidade arbóreo-arbustiva de uma floresta estacional semidecidual em Ingaí, MG. Revista Brasileira de Botânica 25: 195-213.

Brade, A.C. 1956. A flora do Parque Nacional de Itatiaia. Boletim do Parque Nacional do Itatiaia 5: 7-85.

Brower, J.E. \& Zar, J.H. 1984. Field and laboratory methods for general ecology. Dubuque, W.M.C. Brow.
Carvalho, D.A.; Oliveira-Filho, A. T.; Vilela, E.A. \& Gavilanes, M.L. 1995a. Estrutura fitossociológica de mata ripária do alto Rio Grande (Bom Sucesso/MG). Revista Brasileira de Botânica 18: 39-49.

Carvalho, D.A.; Oliveira-Filho, A.T.; Vilela, E.A. \& Gavilanes, M.L. 1995b. Flora arbustivo-arbórea de uma floresta ripária no alto Rio Grande em Bom Sucesso, MG. Acta Botanica Brasilica 9: 231-245.

Clark, D.B.; Clark, D.A.; Read, J.M. 1998. Edaphic variation and the mesoscale distribution of tree species in a neotropical rain forest. Journal of Ecology 86: 101-112.

EMBRAPA. 1997. Manual de métodos de análises de solo. 2.ed. Rio de Janeiro, Empresa Brasileira de Pesquisa Agropecuária, Centro Nacional de Pesquisa de Solos.

EMBRAPA. 1999. Sistema brasileiro de classificação de solos. Rio de Janeiro, Empresa Brasileira de Pesquisa Agropecuária, Centro Nacional de Pesquisa de Solos.

Gentry, A.H. 1995. Patterns of diversity and floristic composition in neotropical montane forests. Pp.103-126. In: S.P. Churchill; H. Balslev; E. Forero \& J.L. Luteyn (eds.). Biodiversity and Conservation of Neotropical Montane Forests: Proceedings of Neotropical Montane Forest Biodiversity and Conservation Symposium. New York, The New York Botanical Garden.

Ivanauskas, N.M. \& Rodrigues, R.R. 2000. Similaridade florística entre áreas de Floresta Atlântica no estado de São Paulo. Brazilian Journal of Ecology 4: 71-81.

Lima, M.P.M. \& Guedes-Bruni, R.R. 1994. Reserva ecológica de Macaé de Cima - Nova Friburgo - RJ: aspectos florísticos das espécies vasculares. Rio de Janeiro, Jardim Botânico do Rio de Janeiro.

McCune, B. \& Mefford, M.J. 1999. PC-ORD version 4.0., multivariate analysis of ecological data, Users guide. MjM Software Design, Glaneden Beach.

Meira Neto, J.A.; Bernacci, L.C.; Grombone, M.T.; Tamashiro, J.Y. \& Leitão-Filho, H.F. 1989. Composição florística da floresta semidecídua de altitude do Parque Municipal da Grota Funda (Atibaia, estado de São Paulo). Acta Botanica Brasilica 3: 51-74.

Metzger, J.P.; Bernacci, L.C. \& Goldenberg, R. 1997. Pattern of tree species diversity in riparian forest fragments of different widths (SE Brazil). Plant Ecology 133: 135-152.

Oldeman, R.A.A. 1983. Tropical rain forest: architecture, sylvigenesis and diversity. Pp. 139-150. In: S.L. Sutton; T.C. Whitmore \& A.C. Chadwick (eds.). Tropical rain forest: ecology and management. Oxford, Blackwell.

Oliveira-Filho, A.T. \& Fontes, M.A.L. 2000. Patterns of Floristic Differentiation among Atlantic Forests in Southeastern Brazil and the Influence of Climate. Biotropica 32: 793-810.

Oliveira-Filho, A.T. \& Machado, J.N.M. 1993. Composição florística de uma floresta semidecídua montana, na Serra de São José, Tiradentes, Minas Gerais. Acta Botanica Brasilica 7: 71-88.

Oliveira-Filho, A.T.; Carvalho, D.A.; Fontes, M.A.L.; van den Berg, E.; Curi, N. \& Carvalho, W.A.C. 2004. Variações estruturais do compartimento arbóreo de uma floresta semidecídua alto-montana na chapada das Perdizes, Carrancas, MG. Revista Brasileira de Botânica 27: 291-309. 
Oliveira-Filho, A.T.; Curi, N.; Vilela, E.A. \& Carvalho, D.A. 2001. Variation in tree community composition and structure with changes in soil properties within a fragment of semideciduous forest in south-eastern Brazil. Edinburgh Journal of Botany 58: 139-158.

Oliveira-Filho, A.T.; Vilela, E.A.; Carvalho, D.A. \& Gavilanes, M.L. 1994a. Differentiation of streamside and upland vegetation in an area of montane semideciduous forest in southeastern Brazil. Flora 189: 1-19.

Oliveira-Filho, A.T.; Vilela, E.A.; Carvalho, D.A. \& Gavilanes, M.L. 1994b. Effects of soils and topography on the distribution of tree species in a tropical riverine forest in south-eastern Brazil. Journal of Tropical Ecology 10: 483-508.

Oliveira-Filho, A.T.; Vilela, E.A.; Gavilanes, M.L. \& Carvalho, D.A. 1994c. Effect of flooding regime and understorey bamboos on the physiognomy and tree species composition of a tropical semideciduous forest in Southeastern Brazil. Vegetatio 113: 99-124.

Robim, M.J.; Pastore, J.A.; Aguiar, O.T. \& Baitello, J.B. 1990. Flora arbóreo arbustiva e herbácea do Parque Estadual de Campos do Jordão (SP). Revista do Instituto Florestal de São Paulo 2: 31-53.

Rodrigues, R.R. 1988. Métodos fitossociológicos mais usados. Casa da Agricultura 10: 20-24.

Rodrigues, R.R. 2000. Uma discussão nomenclatural das formações ciliares. Pp. 91-100. In: R.R. Rodrigues \& Leitão-Filho, H.F. (eds.). Matas ciliares. São Paulo, EDUSP.

Rodrigues, L.A.; Carvalho, D.A.; Oliveira-Filho, A.T.; Botrel, R.T. \& Silva, E.A. 2003. Florística e estrutura da comunidade arbórea de um fragmento florestal em Luminárias, MG. Acta Botanica Brasilica 17: 71-97.

Robim, M.J.; Pastore, J.A.; Aguiar, O.T. \& Baitello, J.B. 1990. Flora arbóreo arbustiva e herbácea do Parque Estadual de Campos do Jordão (SP). Revista do Instituto Florestal de São Paulo 2: 31-53.

Salis, S.M.; Shepherd, G.J. \& Joly, C.A. 1995. Floristic comparison of mesophytic semideciduous forests of the interior of the state of São Paulo, Southeast Brazil. Vegetatio 119: 155-164.

Scudeller, V.V.; Martins, F.R \& Shepherd, G.J. 2001. Distribution and abundance of arboreal species in the Atlantic Ombrophilous Dense Forest in Southeastern Brazil. Plant Ecology 152: 185-199.
Souza, J.S.; Espírito-Santo, F.D.B.; Fontes, M.A.L.; OliveiraFilho, A.T. \& Botezelli, L. 2003. Análise das variações florísticas e estruturais da comunidade arbórea de um fragmento de Floresta Semidecídua às margens do rio Capivari, Lavras-MG. Revista Árvore 27: 185-206.

ter Braak, C.J.F. 1987. The analysis of vegetationenvironment relationship by canonical correspondence analysis. Vegetatio 69: 69-77.

ter Braak, C.J.F. 1995. Ordination. Pp. 91-173. In: R.H.G. Jongman; C.J.F. ter Braak \& O.F.R. van Tongeren (eds.). Data analysis in community and landscape ecology. Cambrigde, Cambrigde University Press.

Toniato, M.T.Z. \& Oliveira-Filho, A.T. 2004. Variations in tree community composition and structure in a fragment of tropical semideciduous forest in southeastern Brazil related to different human disturbance histories. Forest Ecology and Management (no prelo).

van den Berg, E. \& Oliveira-Filho, A.T. 1999. Spatial partitioning among tree species within an area of tropical montane gallery forest in south-eastern Brazil. Flora 194: 249-246.

van den Berg, E. \& Oliveira-Filho, A.T. 2000. Composição florística e estrutura fitossociológica de uma floresta ripária em Itutinga, MG, e comparação com outras áreas. Revista Brasileira de Botânica 23: 231-253.

Veloso, H.P.; Rangel Filho, A.L.R. \& Lima, J.C.A. 1991. Classificação da vegetação brasileira adaptada a um sistema universal. Rio de Janeiro, Instituto Brasileiro de Geografia e Estatística.

Vilela, E.A.; Oliveira-Filho, A.T.; Carvalho, D.A. \& Gavilanes, M.L. 1995. Flora arbustivo-arbórea de um fragmento de mata ciliar no alto rio Grande, Itutinga, Minas Gerais. Acta Botanica Brasilica 9: 87-100.

Vilela, E.A.; Oliveira-Filho, A.T.; Carvalho, D.A.; Guilherme, F.A.G. \& Apolinário, V. 2000. Caracterização estrutural de floresta ripária do Alto Rio Grande, em Madre de Deus de Minas, MG. Cerne 6: 41-54.

Webster, G.L. 1995. The panorama of Neotropical Cloud Forests. Pp. 53-77. In: S.P. Churchill; H. Balslev; E. Forero \& J.L. Luteyn (eds.). Biodiversity and Conservation of Neotropical Montane Forests: Proceedings of Neotropical Montane Forest Biodiversity and Conservation Symposium. New York, The New York Botanical Garden.

Zar, J.H. 1996. Biostatistical analysis, 3. ed. New Jersey, Prentice Hall. 